\title{
Lessons from lockdown: Media discourse on the role of behavioural science in the UK COVID-19 response
}

\author{
Authors: Jet G. Sanders ${ }^{1 *}$, Alessia Tosi ${ }^{2}$, Sandra Obradovic ${ }^{3}$, Ilaria Miligi ${ }^{1}$, Liam Delaney ${ }^{1}$ \\ ${ }^{1}$ Department of Psychological and Behavioural Sciences, London School of Economics and Political \\ Sciences, London, United Kingdom \\ ${ }^{2}$ No affiliation \\ ${ }^{3}$ School of Psychology and Counselling, Faculty of Arts and Social Sciences, The Open University, \\ United Kingdom \\ * Correspondence: \\ Jet G. Sanders \\ j.g.sanders@1se.ac.uk
}

Keywords: behavioural science, COVID-19, behavioural policy, national lockdown, trust in science, corpus linguistics, media discourse analysis, Twitter

\begin{abstract}
In recent years behavioural science has quickly become embedded in national level policy making. As the contributions of behavioural science to the UK's Covid-19 response policies in early 2020 became apparent, a debate emerged in the British media about its involvement. This served as a unique opportunity to capture public discourse and representation of behavioural science in fasttrack, high-stake national policy making. Aimed at identifying elements which foster and detract from trust and credibility in emergent scientific contributions to policy making, in study 1 we use corpus linguistics and thematic analysis to map the narrative around the key behavioural science actors and concepts which were discussed in the 650 news articles extracted from the 15 most read British newspapers over the 12-week period surrounding the first hard UK lockdown from March 2020. We report and discuss 1) the salience of key concepts and actors as the debate unfolded, 2) quantified changes in the polarity of the sentiment expressed toward them and their policy application contexts, and 3) patterns of co-occurrence via network analysis. In Study 2, we investigate how salience and sentiment of key themes observed in traditional media discourse tracked on original Twitter chatter $(\mathrm{N}=2,187)$. In Study 3 , we complement these findings with a qualitative analysis of the subset of news articles which contained the most extreme sentiments $(\mathrm{N}=111)$, providing an in-depth perspective of sentiments and discourse developed around keywords, as either promoting or undermining their credibility in, and trust toward behaviourally informed policy. We discuss our findings in light of the integration of behavioural science in national policy making under emergency constraints.
\end{abstract}

\section{Introduction}


Public trust in the transparency and reliability of scientific evidence is an important component of effective responses to major challenges and crises (Hendriks, Kienhues, \& Bromme, 2015; Pittinsky, 2015). Generally, public perceptions of science are positive: science is often held in high esteem with equally high confidence placed in scientists (e.g., Jonge, 2015; Lamberts, 2017; Lindholm et al., 2018; National Science Board, 2016; Scheufele, 2013; Robert Bosch Stiftung, 2017). However, the application of science in policy has variable success (Sanchèz-Pàramo et al., 2019). Not all science is deemed fit to inform policy (Anvari, Lankens, 2018; Ioannidis, 2018; Stevens, 2020; Cairney, 2020). Determining when a scientific discipline is ready to inform policy is precarious and can be volatile: the criteria for evidence-readiness can vary depending on what is at stake (Ruggeri et al., 2020). In addition, policy is shaped by many pressures other than those based on evidence. Direct competition from other pressures can shape public perceptions and can steer the policy-makers' ability to implement evidence at hand (Cairney, 2020).

In March 2020, the UK was faced with the high-stake policy choice of a national lockdown as Covid-19 spread globally (Kreps and Kriner, 2020). Just like other governments, they had to make this choice in light of the limited available evidence. As scientific evidence about the virus and its effects was sparse, much scientific expertise was drawn on by calling a broad range of scientists onto expert panels to advise (UK Government, 2020). In British policy, unlike many other national governments, one prominent perspective was that of the behavioural sciences.

The integration of behavioural science into UK policy took a number of forms. In particular, the government Scientific Advisory Group for Emergencies (SAGE) developed a behavioural advisory group consisting of prominent UK psychologists, behavioural scientists, and related researchers and policy experts, known as the Scientific Pandemic Influenza Group on Behaviours (SPI-B). The core committee of SAGE also included Dr David Halpern, chief executive of the Behavioural Insights Team (BIT). It is possible that this perspective was particularly wellrepresented in the UK because behavioural sciences has been embedded in British policy for longer and more widely than in other national systems. The UK Cabinet Office was amongst the first to embed a dedicated behavioural science unit (often called the 'nudge unit') to that effect (Sanders et al.,2018). Arguably, it is in part due to the unit that the effect of nudge as a novel policy instrument (Lourenco et al., 2016) and methods to test for their effectiveness (Della Vigna, Linos, 2020) were demonstrable on national policy level and embedded elsewhere. We have since seen an increasing popularity for the policy approach, as evidenced by the growing number of behavioural insight units that advise national governments on issues involving citizen choices in the last 10 years (Whitehead et al., 2014; Halpern, 2015).

Perhaps most relevant to Covid-19, the behavioural sciences, as the study of human behaviour, can provide valuable insights for managing a pandemic that requires changes to human behaviour and everyday interpersonal contact (Van Bavel et al., 2020). Yet, as the role of behavioural science in the lead up to the lockdown decision in the UK became apparent, public debate around its involvement surged. This left the questions: what caused debate about the role of this emergent science, what were its consequences (if any) and how can we learn from the communication around its scientific contributions to this high-stake policy? To address these questions, this paper provides a key case study on trust and acceptability surrounding the contributions of social and behavioural sciences at a time of crisis (e.g., Nadelson et al., 2014, Huber et al., 2019). Covid-19 took place at a time of widespread use of social media, providing an opportunity to understand how reactions were distributed across society through time. While an emerging body of literature exists on support for behavioural interventions (e.g., Reynolds et al., 2019, Sunstein et al., 2019), far less work has been conducted on trust in behavioural scientists more generally, and no work that we are aware of 


\section{Behavioural science representations during COVID-19}

examines public support for the inclusion of behavioural scientists in committees advising government and shaping policy.

To study representations and perceptions of behavioural science over the course of the covid-19 policy response, we initially focus on print media (Study 1), followed by twitter as a popular source of social media to track their adhesion (Study 2). Print media retain a significant role in the formation of public opinion (Van Aelst, 2014). Although social media use has risen significantly in recent years (Gil de Zúñiga et al., 2012), many users merely take their cue from social media to follow-up in (online) newsprint (Dutton et al., 2013; Mitchell et al., 2018). For example, Chew and Eysenbach (2010) show that during the H1N1 pandemic, individuals used Twitter to share resource-related posts, with news media websites being the most popular sources to share. In addition, mass media plays an important agenda-setting role: it can direct collective attention and perceived importance (McLeod et al., 1974), shape how severe an issue is perceived to be, and influence how individuals come to perceive their social and political environment (Tyler, 1980; Protess, \& McCombs, 2016). In other words, mass media play an important 'mediating' role in sharing and shaping how scientific and political expertise is understood by the public (Kim, 2018; Baum and Potter, 2008).

Following from the above, we start with capturing public discourse on the role of behavioural science in this particular policy context in newspaper articles on the topic of behavioural science during the 24-week period surrounding the high-stake policy decision of the first national lockdown in March 2020.

\section{Study 1 Newspaper discourse analysis}

Top newspapers have been shown to sway common understanding of scientific disciplines and can be used as a proxy to measure understanding of their place in public policy (Schäfer, 2012; Bauer et al., 1994; Mutz \& Soss, 1997). As the contributions of behavioural science to the UK's Covid-19 lockdown policies developed, and debate emerged in the British media about its involvement, we reasoned that, in the lead up to, during and after the UK Covid-19 lockdown period in March 2020, public perceptions of behavioural science contributions to this high-stake UK policy decision should be detectable from newspaper articles. With this in mind, we set out to explore the salience, sentiments and co-occurrence of key behavioural science concepts and actors over the lockdown period of 2020 .

\subsection{Materials and methods}

Materials. In order to capture perceptions of behavioural policies, we retrieved news articles from the online database Lexis Nexis for an 8-week window either side of the UK lockdown decision ( $27^{\text {th }}$ of January $2020-10^{\text {th }}$ of July 2020). We drew on the 15 UK newspapers with the highest circulation levels (see Supplementary Material 1).We estimate that articles in these newspapers collectively reached almost 8 million people in print and in digital editions (approximately 12\% of the British population) on a monthly basis (Mayhew, 2020; Worldometer, 2020).

Using a snowball method, we developed a query to identify articles relevant to the discussion of behavioural science (see Supplementary Material 2.A for details). The search produced a corpus of 865 articles. Deduplication and removal of incomplete articles resulted in a sample of 679 articles. These were qualitatively reviewed by three coders for relevance to the topic of behavioural science. This left 647 articles (ranging from 1-47 per news outlet; see Supplementary Material 1 for details) for the quantitative analysis of Study 1 (see Figure 1, left for an overview). 

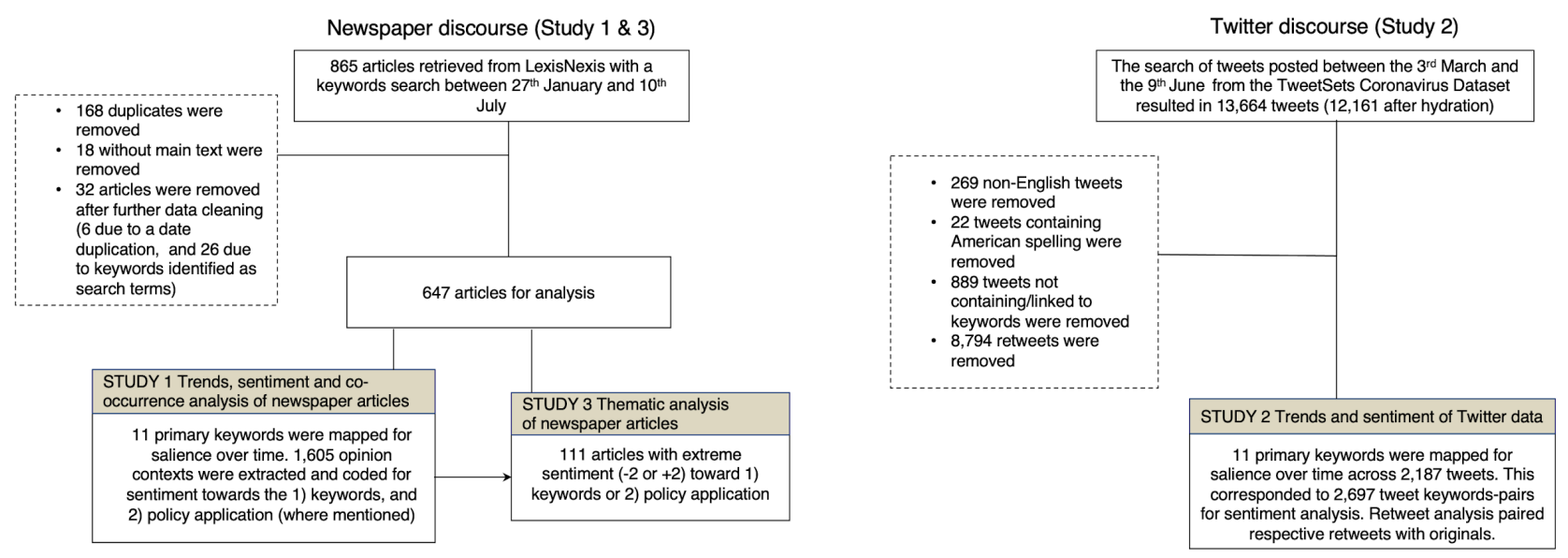

Figure 1: Flowchart of data selection and cleaning process taken for Study 1(left) and Study 2(right), followed by selection of articles for thematic discourse analysis in Study 3.

Keyword processing. We defined an initial set of 42 keywords based on the snowball method applied through the search query, to capture public discourse around behavioural science contributions to policy during this time period (see Supplementary Material 3 for a complete set). As one word can be expressed in different ways (e.g. abbreviated, singular/plural form, or by use of synonyms), keywords were grouped to form primary keywords as follows: 1) plurals were standardised into a singular form: e.g. behavioural science and behavioural sciences as behavioural science; 2) synonyms were unified: e.g. nudge unit and behavioural insights team as behavioural insights team; and 3) we integrated semantically related keywords based on expert knowledge: e.g. nudge, nudging, nudge theory and nudge strategy were noted as nudge. As exceptions to this rule, we kept psychologist, behavioural scientist and behavioural economist as stand-alone primary keywords. As profession names often preface unique actors (as opposed to their plural counterparts, e.g., Professor of Health Psychology Susan Michie VS Professors at Oxford), they lend themselves as proxies for actors not captured in our keyword base.

This resulted in 20 primary keywords: behavioural science, affiliated disciplines (psychology, behavioural economics), behavioural science concepts (nudge, choice architecture, irrational behaviour, behavioural change, behavioural analysis, behavioural insights), commonly named actors in national or international behavioural policy work (SPI-B, Behavioural Insights Team, Michie, Halpern, Chater, Thaler, Sunstein, Kahneman), and unnamed behavioural science actors (behavioural scientist, psychologist, behavioural economist).

Analyses. Salience. To assess the salience of primary keywords over time, we first removed all 'parts-of-speech' apart from nouns or keywords. This is based on the assumption that it is nouns that are the part of speech that represent the content of an article (Stuart, Rayz \& Raskin, 2013). A salience score was calculated for each primary keyword per two-week period. The score was a product of the keyword's normalised corpus frequency (i.e., number of keyword occurrences divided by total word counts per 10,000 words) and the keyword's relative document frequency (i.e., proportion of articles in which the keyword was mentioned). This composite metric allowed us to account for centrality of a keyword in the narrative of the articles published in the 2-week period (normalised corpus frequency), by the spread in the media of the keyword in the period (relative document frequency; Manning et al., 2008). 


\section{Behavioural science representations during COVID-19}

Sentiment. Targeted sentiment analysis was used to assess perceptions of behavioural science applied in national public policy context. We first identified all sentences $(n=1280)$ in our corpus where a behavioural science keyword occurred. As a sentence could contain more than one keyword (median $=1$, range $=1-5$ ), this resulted in a sample of 1605 keyword-sentence pairs, termed opinion contexts. Each opinion context was coded manually for sentiment polarity expressed toward each secondary behavioural science keyword on a 5-point scale from -2 (extremely negative), -1 (moderately negative), 0 (neutral), +1 (moderately positive), +2 (extremely positive). Opinion contexts were also reviewed to contain reference to national-level policy (e.g., mention of government, minister, no. 10, see Supplementary Material 3 for a full list). When this was the case, sentiment polarity toward the policy actor applying behavioural science was also rated.

Three independent coders coordinated to produce an intercoder agreement for a subset of cases. To match salience scoring, results were presented for two-week intervals over the period of the first national lockdown of 2020 in three sentiment categories: negative $(-1 ;-2)$, neutral $(0)$ and positive $(+1 ;+2)$.

Co-occurrence. Finally, we used keyword co-occurrence analysis to investigate and quantify the association strength between keywords: strong associations indicate that keywords 'belong to' the same narrative, whilst weak associations indicate that keywords do not (Callon et al., 1983; Choi, Yi $\&$ Lee, 2011). This method allowed us to capture how the conceptual structure of the public narrative around behavioural sciences evolved over the period of the first national lockdown. To allow for reasonable variance in co-occurrence, we opted to move from two-week windows to a pre-, duringand post-lockdown window of analysis.

Co-occurrence between any two keywords was calculated at the article level and expressed by the Dice coefficient: the ratio between the co-occurrence of two keywords and the sum of their individual occurrences multiplied by two (Frakes \& Baeza-Yates 1992; see Supplementary Material 6 for details). Simply put, two keywords that never co-occur have a coefficient of 0 and two keywords with identical occurrence have a coefficient of $1^{1}$. We visualised the keyword association network structures, one for each time window, where keywords are displayed in nodes and edge weights reflect the strength of their co-occurrence with others (Katsurai \& Ono, 2019; Kim et al., 2020; Liu et al., 2012) using the Python NetworkX 2.5 library (Hagberg et al.2008).

To understand how the relationships between keywords evolved, we calculated and compared the following network- and node-level metrics (Sudhahar et al., 2015):

(a) Network density: the ratio of the actual number of links between keywords to the maximum possible number of links. On a scale from 0 to 1 , higher value indicates a cohesive network.

(b) Node weighted degree centrality: the sum of the edge weights for edges incident to that keyword. Higher values indicate more frequent direct links to other keywords.

(c) Node weighted between centrality: the degree to which a keyword stands between others. Higher values indicate greater importance in bridging subsets of keywords.

\footnotetext{
${ }^{1}$ Note the dice coefficient is influenced by co-occurrence, but also by the individual frequency of the two keywords. Thus, the Dice coefficient can be high even when the co-occurrence is relatively small. For example, if two keywords have overall low frequency but they almost always appear together whenever they appear in an article. To minimise any misrepresentations, we only used the dice coefficient analysis for keywords $n>20$.
} 
Finally, the changing trend of important keywords in the network was identified by comparing the ranking of keywords for the node centrality metrics (b) and (c) of the three different time periods.

\subsection{Results}

From all analyses we excluded 9 keywords due to extremely low overall frequency $(<30$ occurrences over the 24-week period of interest; see Supplementary Material 5.A for details) as they did not provide enough data points across time to determine trends in our metrics of interest. This left 11 primary keywords: behavioural science, the discipline terms behavioural economics and psychology, four of the eight named actors (Behavioural Insights Team, Halpern, Michie, and SPI-B), two of three unnamed actors (behavioural scientist and psychologist), and two of six concept terms (behaviour change and nudge).

Below, we present trends in salience and sentiment towards behavioural-science keywords over time, followed by reference and sentiment toward public policy application and co-occurrence. As frequently the case in descriptive exploratory studies of linguistic data (e.g., Bian et al., 2016; Kim et al., 2020; Sharma et al., 2020), we contain our results to descriptive findings.

\subsubsection{Salience and sentiment of keywords over time}

Primary keyword behavioural science showed two clear surges: the first started one month prior to the UK lockdown (-2) and ended just after lockdown $(+1)$ and the second rather spike-like surge occurred within a two-week period one month after the 'hard' UK lockdown measures eased (+6; see Figure 2 and Supplementary Material 4). Simultaneous to the surges, we see an increase in polar sentiments: positive and negative sentiments are greater during these periods as compared to other time-periods. This pattern is reminiscent of one commonly reported: 'conflict' is deemed of news value and determines the extent to which journalists pay attention to politics (Van der Pas \& Vliegenthart, 2016; Galtung \& Ruge, 1965; Harcup \& O’Neill, 2001). 


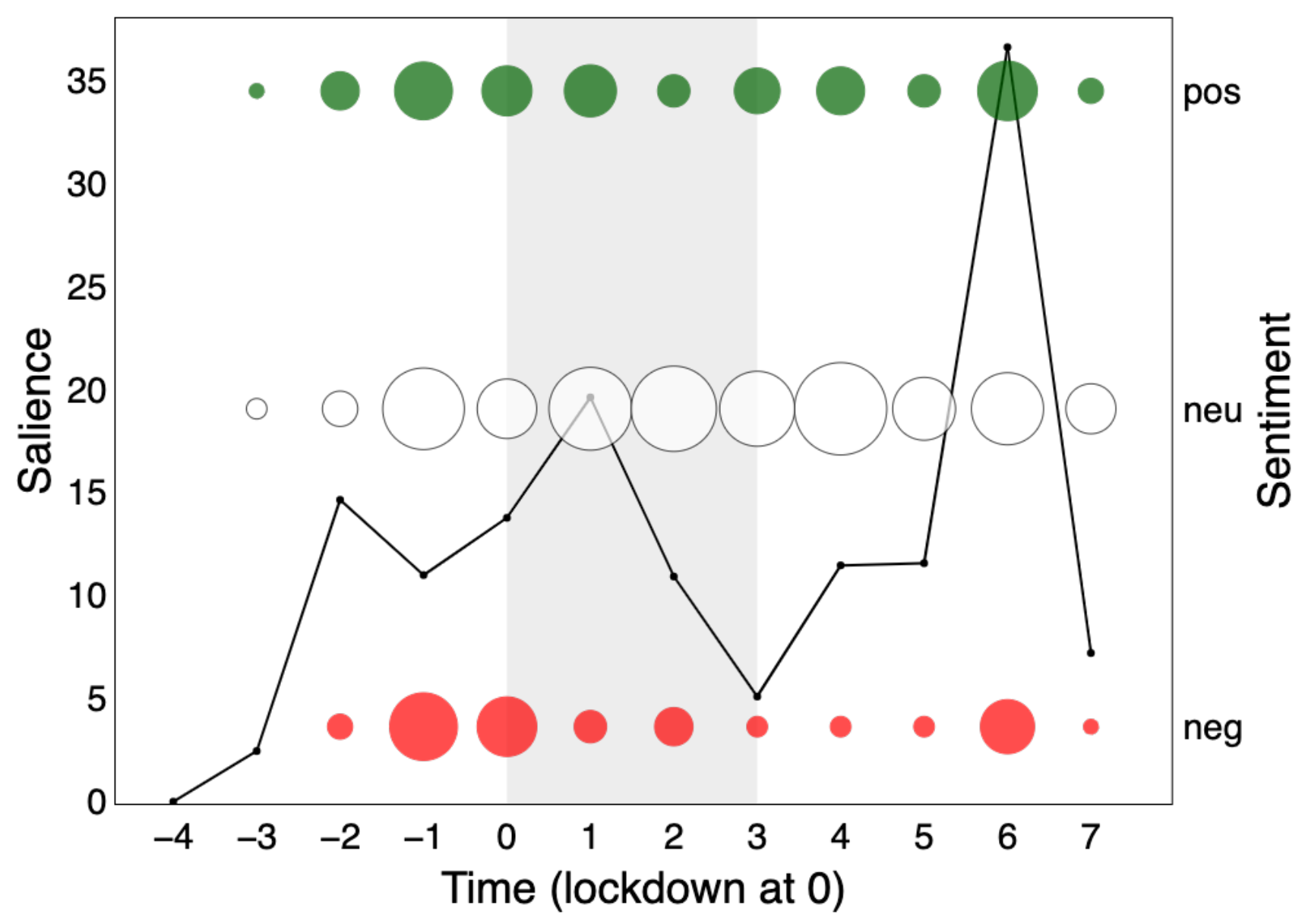

Figure 2: Salience of and sentiment towards the keyword 'behavioural science' over a 12 two-week time-period surrounding the first British national lockdown of 2020 (grey area) in print media (top 15 UK newspapers). Salience is calculated for a 2-week period as the normalised keyword frequency (per 10,000 words) multiplied by the proportion of articles that mention the keyword. The size of the bubble is proportional to the count of sentiments in that polarity class towards the keyword.

What seems to associate with the observed divisiveness? Discipline terms and unnamed actors do not show similar sentimental surges. Psychology (Figure 2I) seems to show a subdued version of behavioural science salience, with notably greater positive than negative sentiment. Behavioural economics is in fact largely absent from the narrative, with minimal salience in newspaper articles, but stable polarity over time.

Similarly, unnamed actors, such as psychologist (Figure 3H) or behavioural scientist (Figure 3D) do not share the surges in sentiment polarity observed for behavioural science. Although unnamed actors show a slight uptick in salience, they show a relatively steady (mostly neutral) sentiment.

We reach a different conclusion for named actors and concept terms. Salience for keyword Michie also mimics the behavioural science trend over time in subdued form, but with positive polarity during the first surge (-1). Keywords Halpern and Behavioural Insights Team show a nearly identical rise in salience to behavioural science in the period leading to lockdown, but rather eliciting a negative response. All actors thus seem to associate with the divisiveness we observe, possibly 
holding opposite perspectives. This narrative finds support in that all three actors only seem to emerge as public figures of behavioural science only around this pre-lockdown time period (-1).

A final pattern of divisiveness is aligned with the keyword nudge. Although nudge was not nearly as salient as other primary keywords, we observe negative sentiment during the first surge. In fact, nudge is the only primary keyword, which throughout the 24-week period attracted more divisiveness than neutrality. Moreover, nudge, Halpern and Behavioural Insights Team are the only primary keywords to show greater negative than positive polarity.

What seems to associate with the observed non-divisiveness/neutrality? We are particularly interested in capturing patterns of neutrality as many may deem this to be the category of sentiment best suited to scientific discussion. Here we make three additional observations: 1) keywords Michie and SPI-B (emerging mid-lockdown) showed increasing presence over time but managed to maintain neutrality. Notably, Michie also attracted a small but sustained quantity of positivity over the full period; 2) psychology (with a stable and lowered presence in the media) shows to maintain a neutral presence over time and 3) behaviour change seems to be largely absent from the narrative, we see a small surge at the point of lockdown ( 0 ; one week after the first surge), possibly aligned with an expected moment in time where many needed to change their behaviour. See Supplementary Material 4 for more detail.
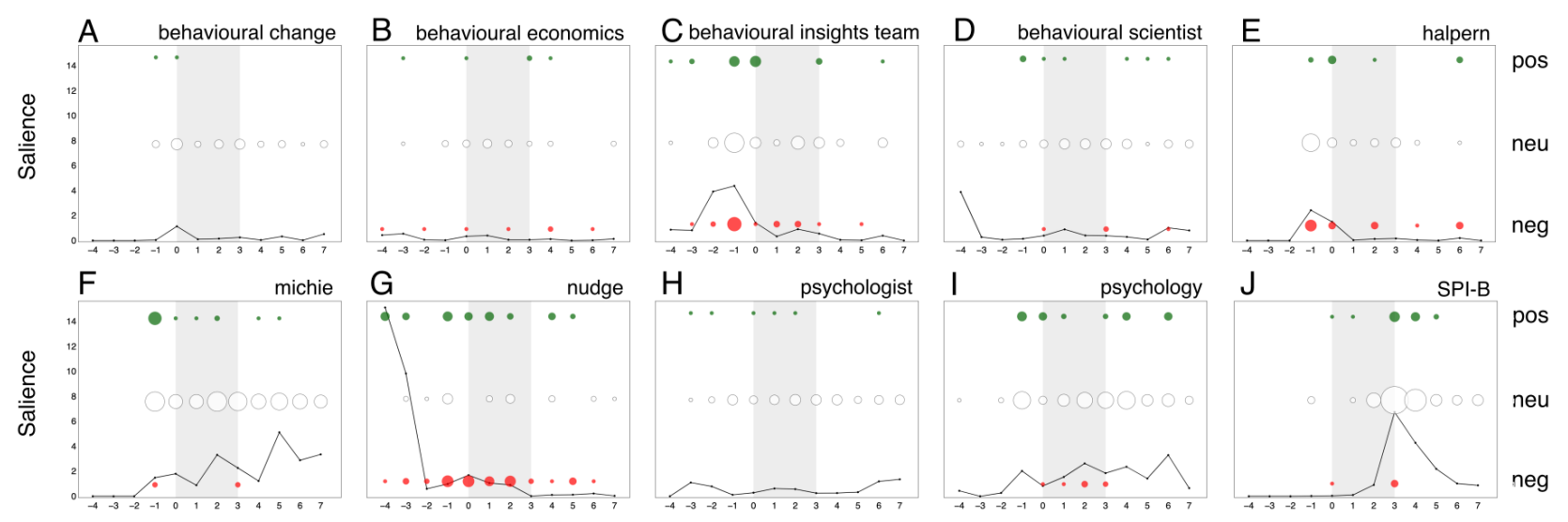

Time (lockdown at 0)

Figure 3: Salience of and sentiment towards the 10 primary keywords over the 12 two-week time period surrounding the first British national lockdown of 2020 (gray area) in print media (top 15 UK newspapers). (A) behaviour change (concept), (B) behavioural economics (discipline), (C) behavioural insights team (named actor), (D) behavioural scientist (unnamed actor), (E) halpern (named actor), (F) michie (named actor), (G) nudge (concept), (H) psychologist (unnamed actor), (I) psychology (discipline), (J) SPI-B (names actor). Salience is calculated per 2-week period as the normalised term frequency (per 10,000 words) multiplied by the proportion of articles that mention the keyword. The area of the bubbles is proportional to the count of sentiments towards the keyword.

Finally, we note that our primary keywords do not provide insight into the second surge in divisiveness in behavioural science (aside from increased salience without sentimental fluctuation for Michie (+6) over this period), which lead to a qualitative inspection of the category of unnamed actors and resulted in identification of an additional key actors: Prof. Stephen Riecher 
(supplementary keyword: Reicher; see Figure 4). Further attention was paid to this in the qualitative analysis (Study 3).

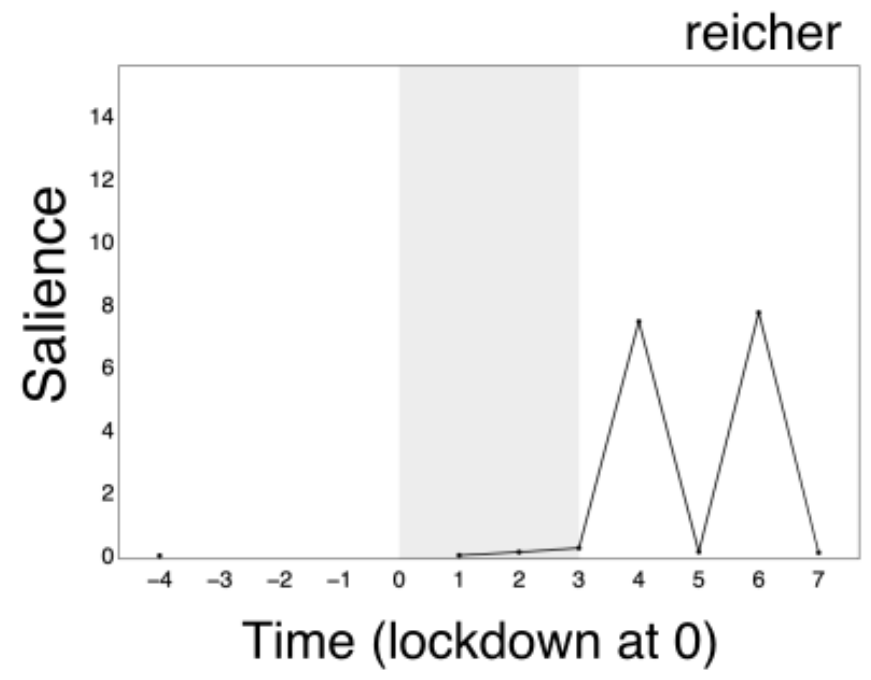

Figure 4: Qualitative inference identified Stephen Reicher as an additional actor. Reicher emerged on the topic of behavioural science toward the latter part of the 24-week time period, corresponding with a surge in salience $(+6)$.

\subsubsection{Sentiment toward keywords in context of public policy application}

We complement our understanding of sentiment expressed toward keywords by separating sentiments by those opinion contexts that refer to the application of behavioural science in public policy and those that do not. We display sentiments in three panels (see Figure 5): keyword sentiment when policy was not mentioned (top), keyword sentiment when policy was mentioned (middle), and sentiment toward policy application in those same opinion contexts (bottom; see data in Supplementary Material 7 and 8).

For behavioural science, we observe similar oscillation over time in all three panels, with two noteworthy differences between panels. First, we note higher neutrality and lower negativity towards behavioural science in opinion contexts which did not mention policy application (62\% of neutral and $15 \%$ of negative sentiments overall) compared to those which did $(52 \%$ of neutral and $22 \%$ of negative sentiments overall). In both contexts, the proportion of neutral sentiments towards behavioural science increased in the lockdown period (from $47 \%$ to $65 \%$ in contexts that did not mention policy and from $40 \%$ to $54 \%$ in contexts that did) and remained the highest post-lockdown. When we compare the sentiments toward behavioural science and its related policy actors in contexts in which both were mentioned (middle, bottom): we observe a much higher (57\% overall) proportion of negative sentiments towards the policy actors, increasing across the three time-windows $(37 \%$ prelockdown, $42 \%$ during lockdown, $82 \%$ post-lockdown), paired with a decreasing proportion of neutral sentiments ( $60 \%$ to $40 \%$ to $15 \%$ post-lockdown). In opposition, the proportion of negative sentiment towards behavioural science shows a decreasing trend (from $37 \%$ to $19 \%$ to $18 \%$ ). This suggests a transference of negative sentiment from the science of behaviour to the actors who apply it in this high-stake policy context over time, for sentences that mention policy application. In other words, we do not only see a greater proportion of negativity toward behavioural science when 
mentioned in a policy context, than when it is not, but we also see that the majority of this negativity is expressed toward the policy actors, and not behavioural science in itself.
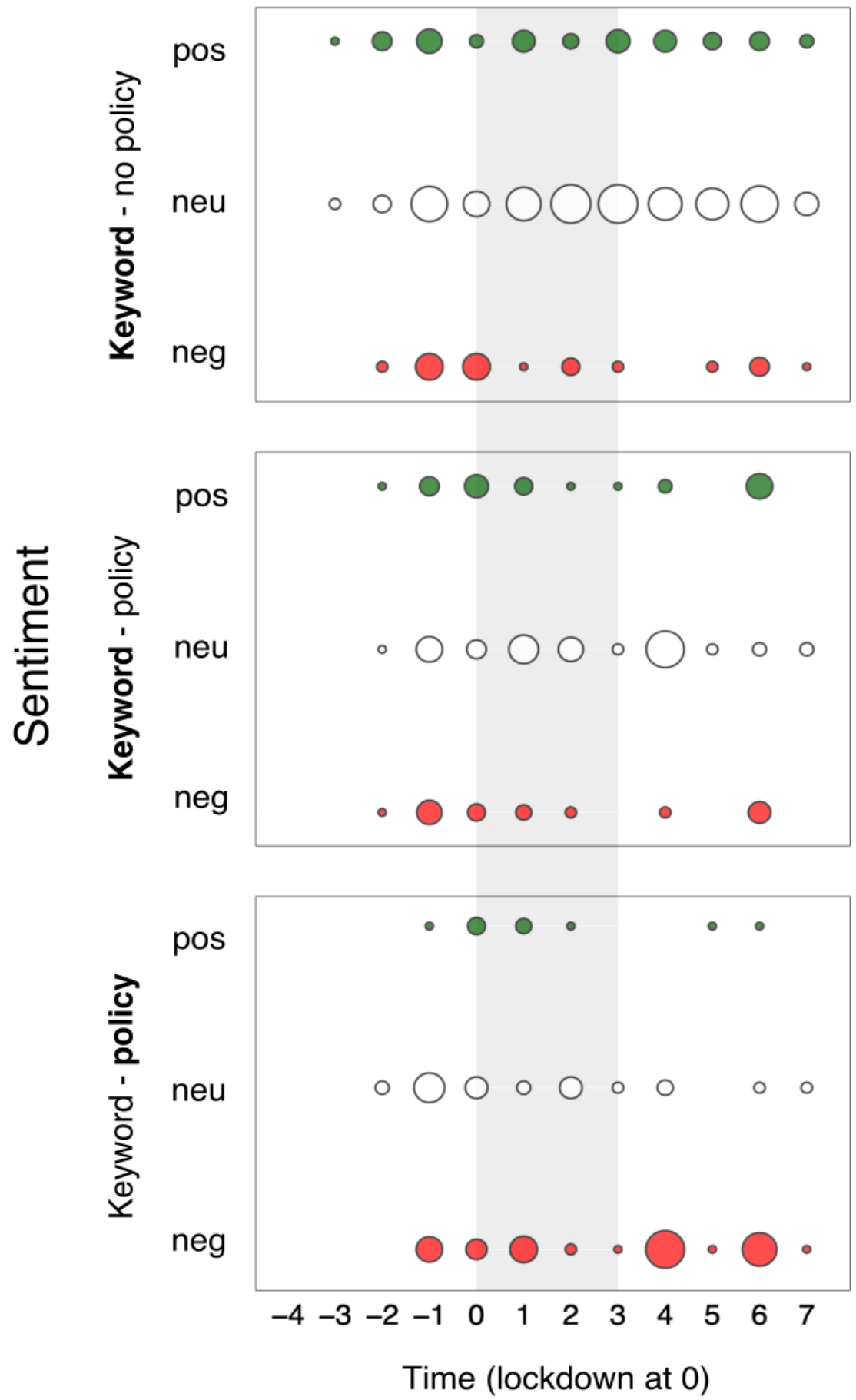

Figure 5: Sentiment towards "Behavioural Science" separated by sentences that do not (top) and do refer to national policy application (middle), and sentiment toward policy contexts of keywords (bottom) over the 12 two-week time period surrounding the first British national lockdown of 2020 from newspaper articles. The area of the bubbles is proportional to the count of sentiments towards the keyword. Reference category in bold. 


\section{Behavioural science representations during COVID-19}

What may result in the transference of negativity from behavioural science to the policy makers who use it? For sentiments expressed toward keywords in sentences that do not refer to policy application (Figure 6, top row) we recount two observations. First, negative sentiment expressed toward behavioural science not in reference to policy, the picture is rather simple: prominent negativity is only observed around the concept of nudge ( $46 \%$ negative sentiments overall). This divisive, negative leaning pattern shows a small but consistent presence over the 24week period, with a negative flare in the lead up to and throughout lockdown (echoed in articles which do mention public policy). Second, most keywords were more likely to appear in contexts that do not mention policy application (range $60-94 \%$ of their occurrences). The exceptions (unsurprisingly) Behavioural Insights Team and Halpern, which appeared in relation to policy actors in $69 \%$ and $63 \%$ of their occurrences respectively. In opinion contexts where policy was not mentioned, all keywords (aside from nudge) were discussed in neutral opinion contexts most often.

For articles that do mention policy application (Figure 6, middle row) and the sentiment towards policy (bottom row), we see a transference of negativity when mentioned alongside policy actors for 9 out of 10 keywords (just as behavioural science). We also observe two patterns: mentions of the common named actors Behavioural Insights Team, Halpern and concept nudge share approximately equal numbers of negativity with the paired policy actors, suggesting a level of coupling pre-lockdown $(-2,-1)$. This whilst discussion of actor Michie seemed to avoid negativity nearly entirely at cost to their policy co-mentions, suggesting a level of contrasting pre- $(-2,-1)$, and mid- to end- lockdown (2-5). The latter pattern is echoed over the same time periods by a small but noticeable number of unnamed actors (behavioural scientist and psychologist) suggesting that a group of scientists may be 'speaking out' against behavioural science application in policy.

The contrasting narrative offers insight into the drivers of a second surge in behavioural science divisiveness (+6). We observe that psychologist, psychology and SPI-B collectively maintain neutrality, but share in negative sentiment expressed towards the co-mentioned policy application (bottom) in the post-lockdown period.

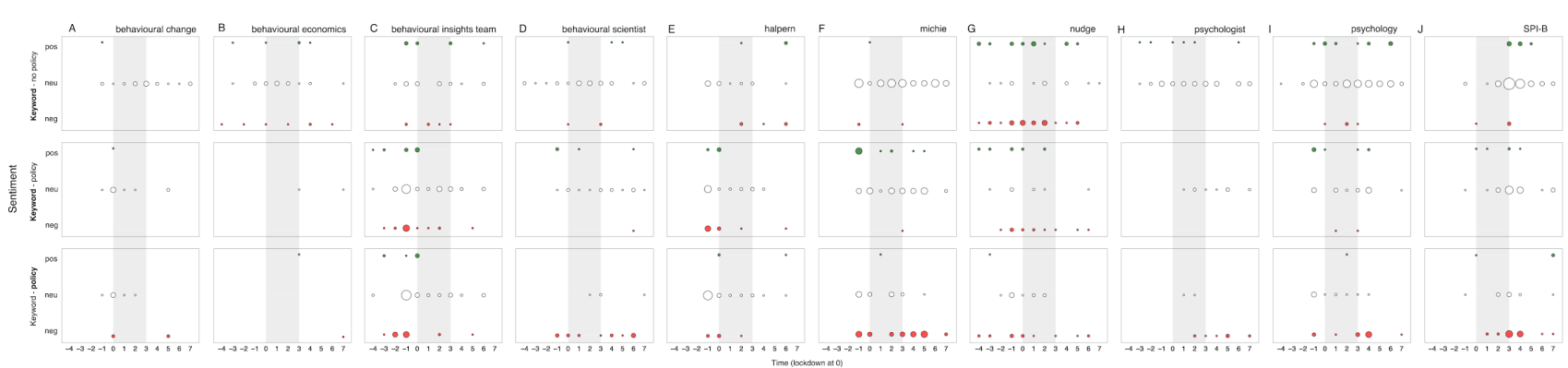

Figure 6: Sentiment towards the 10 primary keywords separated by sentences that do (top row) and do not refer to public policy application (middle row), and sentiment toward policy actors of keywords (bottom row) over a 12 two-week time period surrounding the first British national lockdown of 2020 in newspaper articles. The area of the bubbles is proportional to the count of sentiments towards the keyword. Reference category in bold.

\subsubsection{Co-occurrence between keywords}

Finally, we look at which keywords, actors and concepts frequently co-occur in articles with one another, complemented by four types of metrics: network density, network clustering, node degree centrality, and node betweenness centrality. To allow for frequencies high enough to measure 
co-occurrence (see Supplementary Material 5.A), we opted to look at three time periods: pre-, duringand post- (hard) lockdown (Figure 7; Table 1).

The network structure (see Table 1). Over the hard lockdown period we observe a stronger network density (pre=.56; during=.87; post $=.64$ ) and stronger clustering coefficient (pre=.70; during $=.91$ post $=.79$ ). This suggests that keywords were more frequently discussed in contexts with most other keywords, but also consisted of more individual communities of keyword themes ("highly related keywords"). Across time periods, psychology is the most central keyword (degree centrality), and behavioural science remains in the top 2 for connecting independent clusters of keywords (betweenness centrality). Notably, the other discipline in our set of keywords, behavioural economics, bears no structural importance in any of the networks.

Co-occurrence offers three additional insights: Behavioural Insights Team surges to a central role (degree centrality) and in bridging subset of keywords (betweenness centrality) during lockdown and then moves further down the rank post-lockdown. Michie appears prominent pre- and postlockdown (degree centrality) but has no role in bridging clusters of keywords. Behaviour change and $S P I-B$ slowly emerge into centrality post-lockdown, but neither is of structural importance in any of the three time-windows.

Trends in strength of association (see Figure 7). Pre-lockdown sees two strong associations: Halpern coupled with Behavioural Insights Team, and Michie coupled with psychology (also connected but to a lesser degree with behavioural scientist and behaviour change). During- and postlockdown, we observe that the prior of the two associations is mostly stable (with nudge increasing in association to Halpern and Behavioural Insights Team), whilst the latter shifts: Michie becomes much more frequently associated with behaviour change and no longer with psychology. Finally, we observe that SPI-B slowly solidifies as a third emerging cluster with increasing co-occurrence with behavioural science and psychology. For other relationships see Supplementary Material 6.

\begin{tabular}{|c|c|c|c|}
\hline & $\begin{array}{l}\text { Pre-lockdown } \\
\text { (27 Jan - } 22 \text { Mar) }\end{array}$ & $\begin{array}{l}\text { Lockdown } \\
\text { (23 Mar - } 09 \text { May) }\end{array}$ & $\begin{array}{l}\text { Post-lockdown } \\
\text { (10 May - } 10 \text { July) }\end{array}$ \\
\hline Network density & 0.56 & 0.87 & 0.64 \\
\hline $\begin{array}{l}\text { Network average } \\
\text { clustering } \\
\text { coefficient }\end{array}$ & 0.70 & 0.91 & 0.79 \\
\hline $\begin{array}{l}\text { Weighted degree } \\
\text { centrality } \\
\text { (descending rank) }\end{array}$ & $\begin{array}{l}\text { psychology } \\
\text { michie } \\
\text { behav._insights_team } \\
\text { psychologist } \\
\text { nudge } \\
\text { halpern } \\
\text { behav._change } \\
\text { behav._science } \\
\text { behav._scientist } \\
\text { behav. economics } \\
\text { SPI-B }\end{array}$ & $\begin{array}{l}\text { psychology } \\
\text { behav_insights_team } \\
\text { behav_science }(+) \\
\text { halpern }(+) \\
\text { psychologist } \\
\text { nudge }(-) \\
\text { michie }(-) \\
\text { behav. change } \\
\text { behav. scientist } \\
\text { SPI-B } \\
\text { behav. economics }\end{array}$ & $\begin{array}{l}\text { psychology } \\
\text { michie (+) } \\
\text { behav_science } \\
\text { psychologist } \\
\text { behav_change (+) } \\
\text { SPI-B } \\
\text { behav_insights_team (-) } \\
\text { halpern (-) } \\
\text { behav_scientist } \\
\text { nudge } \\
\text { behav_economics }\end{array}$ \\
\hline $\begin{array}{l}\text { Weighted } \\
\text { betweenness }\end{array}$ & $\begin{array}{l}\text { behav_science } \\
\text { psychology }\end{array}$ & $\begin{array}{l}\text { behav_insights_team }(+) \\
\text { behav_science }\end{array}$ & $\begin{array}{l}\text { psychology } \\
\text { behav_science }\end{array}$ \\
\hline
\end{tabular}




\begin{tabular}{|c|c|c|c|}
\hline $\begin{array}{l}\text { centrality } \\
\text { (descending rank) }\end{array}$ & $\begin{array}{l}\text { nudge } \\
\text { psychologist } \\
\text { michie } \\
\text { behav_insights_team } \\
\text { behav_change } \\
\text { halpern } \\
\text { behav_economics } \\
\text { behav_scientist } \\
\text { SPI-B }\end{array}$ & $\begin{array}{l}\text { halpern }(+) \\
\text { psychologist } \\
\text { psychology } \\
\text { behav_change } \\
\text { nudge (-) } \\
\text { behav_scientist } \\
\text { michie (-) } \\
\text { SPI-B } \\
\text { behav economics }\end{array}$ & $\begin{array}{l}\text { behav_scientist }(+) \\
\text { psychologist } \\
\text { nudge }(+) \\
\text { behav_change } \\
\text { michie } \\
\text { SPI-B } \\
\text { behav_economics } \\
\text { behav_insights_team }(-) \\
\text { halpern }(-)\end{array}$ \\
\hline
\end{tabular}
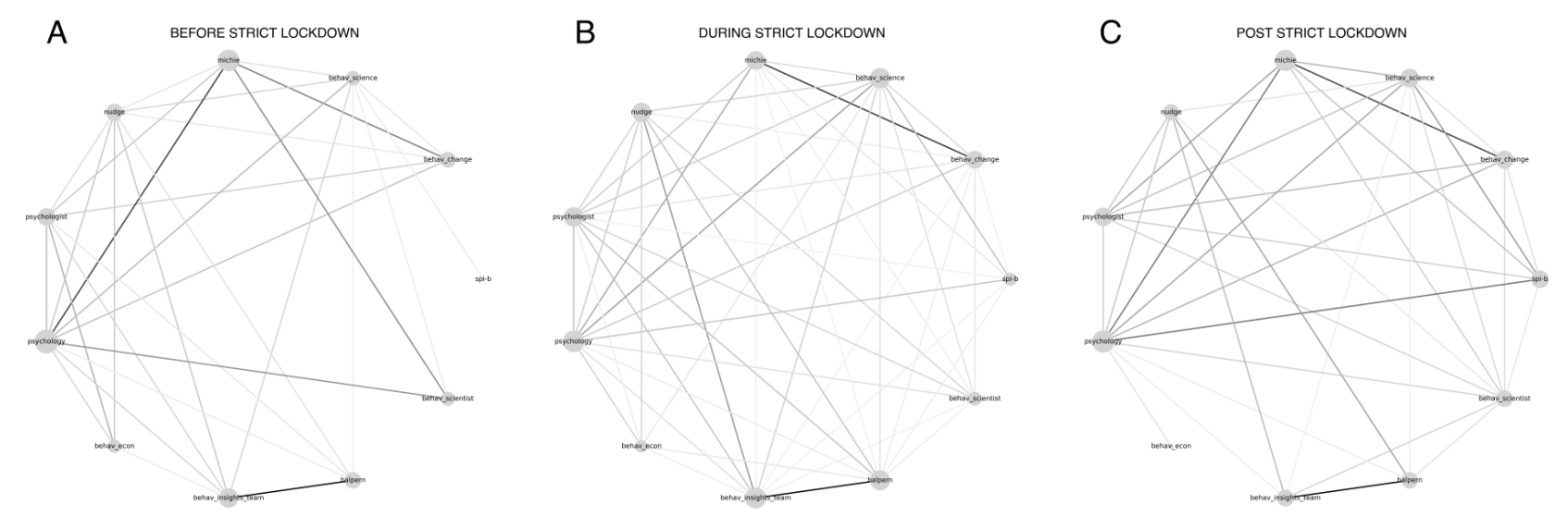

Figure 7: Networks of keyword co-occurrence across the three time periods: pre-lockdown (A), during lockdown $(\boldsymbol{B})$, and post-strict lockdown $(\boldsymbol{C})$. Each node represents a keyword. Edgelines represents the strength of the co-occurrence (Dice coefficient) between two keywords. The node size represents the keyword's weighted degree centrality, the number of neighbouring nodes connected to that node.

\subsection{Discussion}

Our results map the discourse of behavioural science around the UK lockdown decision through trends in keywords and sentiment toward them. We conclude that increased salience can be linked to divisiveness in sentiment, associated with a cluster between Behavioural Insights Team and Halpern (and later also nudge) coupled with policy application of behavioural science in the first (prelockdown) wave. This coupling may be a reflection of the embedded relationship between application of behavioural science in governance and the work of BIT. Whilst their collaboration has allowed advancement of applying the science of behavioural science in many public policy areas, one possibility is that the tight relationship was deemed less acceptable under the high-stake policy conditions which were faced.

Nudge, regardless of whether it was coupled with policy application of behavioural science, also seems to stir divisiveness. This may be a sticking point for trust and credibility in the public eye which seems, to a degree, to be generalisable (Hagman et al., 2015; Treger, 2020). Other than that, the application of behavioural science in high-stake policy incurred relatively high negativity in media discourse, but this did not reflect necessarily on the science of behaviour, but rather in reference to its policy counterpart. In relation, a second cluster of associations seems to have been 
impactful. Key actors such as Michie, Reicher, SPI-B and the unnamed psychologist and behavioural scientist contrasted positively to behavioural science application in national-level governance. This suggests that one of the factors to have played into the trust and credibility of behavioural science (and its readiness for policy application) emanated from behavioural science actors themselves speaking out against its potential misuse as a policy tool under the high-stakes circumstances, and this seemed of particular influence a few weeks after the lockdown started to ease.

\section{Study 2 Social media discourse analysis}

\subsection{Introduction}

In Study 1, we looked at patterns of salience and sentiment toward behavioural science in newspaper articles over the 24-week period surrounding the first UK lockdown of 2020. This analysis does not tell us how the public responded to these articles. In Study 2, we thus identified a set of publically available Twitter data to examine whether and how these stories were picked up over the same time period. Twitter is amongst the most frequently used social media to investigate public's perceptions across a range of topics (Arribas-Bel et al. 2015; Bian et al., 2016; Bibo et al. 2014; Ordun et al. 2020; Sharma et al., 2020). We reasoned that mapping the salience and sentiments of the identified behavioural science concepts and actors from Study 1 over the same time period in this set, would allow us to identify the nature and extent of concordance of public opinion expressed online with that expressed on print media.

\subsection{Materials and methods}

Materials. We used the Coronavirus Tweet Ids Version 7 dataset (Kerchner \& Wrubel, 2020) from TweetSets, the archive of Twitter datasets for research and archiving managed by George Washington University (Littman, 2008). The Coronavirus dataset contains the tweet IDs of 239,861,658 tweets related to COVID-19, collected between March 3, 2020 and June 9, 2020 from the Twitter API using the tags "coronavirus", "COVID-19", "epidemiology", "pandemic". This set was selected, as it was the open-source dataset of tweets that most closely reflected the timeframe and context of the news articles retrieved for Study 1.

Similar to Study 1, we developed a query to identify tweets relevant to the discussion of behavioural science and its application to public policy during the covid-19 pandemic (see Supplementary Material 2.B for details). Our query resulted in a dataset of 13,664 tweet IDs, corresponding to around $0.006 \%$ of the initial dataset. We then used Hydrator (Documenting The Now, 2020) to hydrate these tweets IDs, i.e., retrieve the text of the tweets and associated metadata from the Twitter API, which resulted in 12,161 tweets.

We removed retweets $(8,794)$ using regular expressions to focus the analysis on original tweets as retweets can inflate the number of unique messages for the sentiment analysis. 269 tweets that were not in English were also excluded. Of the remaining tweets, 462 contained no behavioural science keyword (the keyword was mentioned in another tweet linked from within the tweet) and 427 other tweets only contained coronavirus-related search queries but no behavioural science keywords: they were all excluded from analysis. Finally, we also removed 22 tweets that displayed American spelling of behavioural science keywords (e.g., behavioral science). We analysed the remaining 2,187 tweets, corresponding to 2,697 keyword-tweet pairs. See Figure 1 (right) for a step-by-step. 


\section{Behavioural science representations during COVID-19}

Keyword processing. To allow for comparison, we focused our analyses on the 11 primary keywords retained for analysis in Study 1 (see Supplementary material 3 and 5.B for details).

Analyses. Salience. We used document frequency (the proportions of tweets within a 2-week period in which the primary keyword occured) as our measure of salience for the Twitter data. This differs from Study 1 (where we used document frequency multiplied by normalised term frequency): on Twitter, keywords tend to appear once per tweet (of 2,697 keyword occurrences, only $122(4.5 \%)$ contained the same keyword more than once), and the number of total words per tweets is limited (max. 280 characters) and highly consistent (median $=32$ words; IQR $=16$ words). To assess salience over time we calculated two metrics: (i) Salience (original tweets only): the proportion of total tweets in a given fortnight in which the keyword occurred. (ii) Salience (accounting for retweets): the proportion of total tweets and retweets in a given fortnight in which the keyword occured.

Sentiment. We coded sentiment towards keywords and public policy in original tweets as per Study 1 but report two sentiment measures: (i) Sentiment (original tweets only): the count of positive / neutral / negative sentiments towards a keyword per 2-week period; and to account for the reach of sentiment expressed we also calculate (ii) Sentiment (accounting for retweets) by multiplying each sentiment by the number of times the tweet that contained it was retweeted. ${ }^{2}$

\subsection{Results}

\subsubsection{Salience and sentiment of keywords over time}

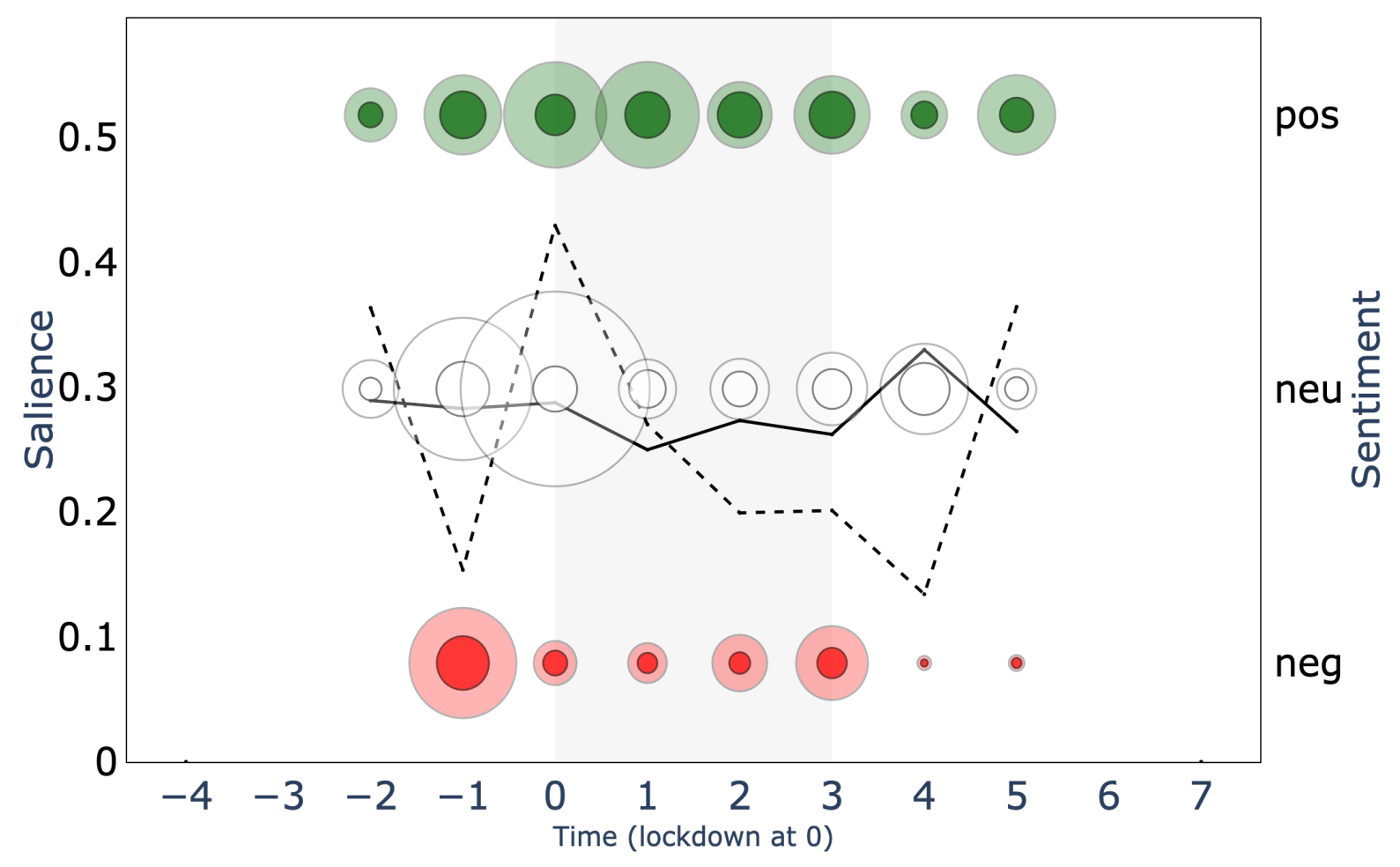

\footnotetext{
${ }^{2}$ For instance, if in a given 2-week period 4 tweets were published, each with a certain number of retweets, and KwordA appeared in 3 of them as follow: tweet 1a | retweets: $10 \mid$ kwordA: 1tweet 2a | retweets: $5 \mid$ kwordA: 1tweet 3a| retweets: 0 | kwordA: 1tweet 3a| retweets: $1 \mid$ kwordA: 0 . Salience (original tweets only) for kwordA in this fortnight would be: $3 / 4=0.75$. Salience (incl. retweets) for kwordA in this fortnight would be: $[(1+10)+(1+5)+(1+0)] /(4+16)=18 / 20=0.9$
} 
Figure 8: Salience and sentiment of 'Behavioural Science' over the 8 two-week time-period surrounding the first British national lockdown of 2020 (grey area) in Twitter data. Salience is calculated as the proportion of tweets in that 2-week period that mention the keyword. Bold line represents salience in original tweets only; Dotted line represents salience accounting for retweets also. The area of the bubbles is proportional to the count of sentiments (red =-2, -1 ; white $=0$; green $=+1,+2)$. Full-colour bubbles represent sentiments in original tweets only; shaded-colour bubbles represent sentiments accounting for retweets.

With regard salience, Figure 8 shows a notably stable trend in original tweets over time, but when we include retweets (dotted line), we observe a pattern largely similar to that of newspaper articles: two surges, one during the fortnight at the start of lockdown (0) and one post-lockdown (5). See also Supplementary Material 9.

Regarding sentiments, original tweets that mention behavioural science attract similar levels of divisiveness in the two weeks prior to lockdown (-1; 37\% neutral; $27 \%$ positive; $36 \%$ negative) and at the end of lockdown (3; 34\% neutral, $46 \%$ positive and $20 \%$ negative) as compared to our set of newspaper articles. Negative sentiments also similarly reduce as the lockdown eases. We do note higher levels of positive and neutral sentiments, which remain relatively constant throughout the entire period, with a noticeable surge in neutral retweets just prior to the start of lockdown $(-1=52 \%$ of all sentiments; $0=74 \%$ of all sentiments).
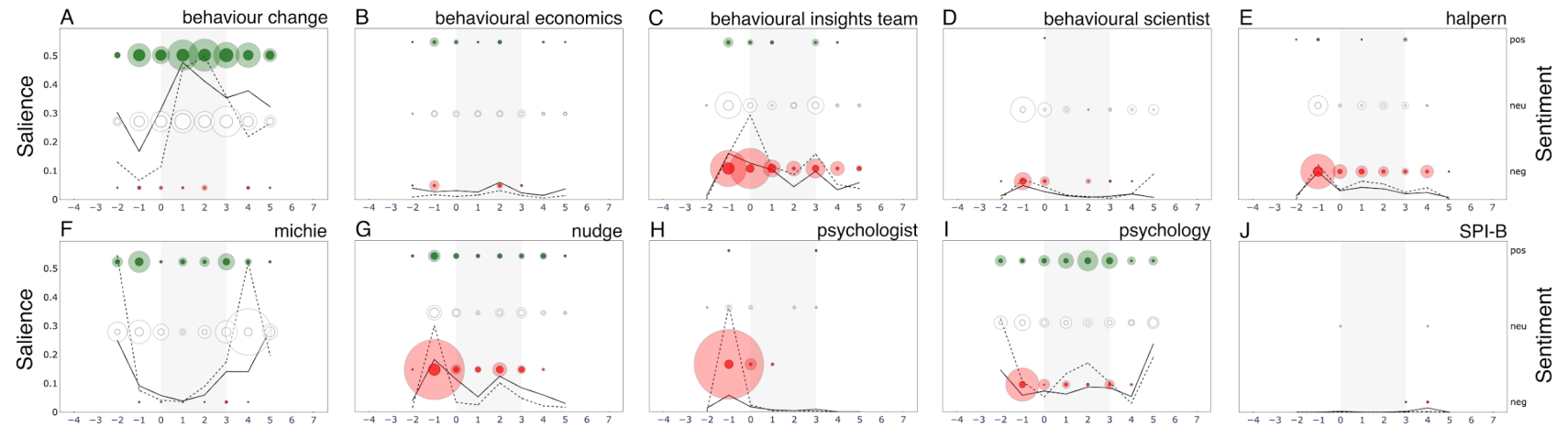

Figure 9: Twitter - Salience of and sentiment towards primary keywords over 8 two-week time-period surrounding the first British national lockdown of 2020 (in grey): (A) behaviour change (concept), (B) behavioural economics, (C) behavioural insights team (named actor), (D) behavioural scientist

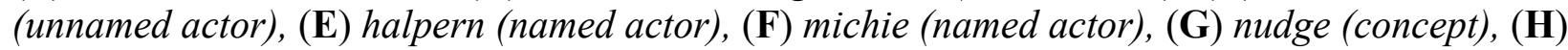
psychologist (unnamed actor), (I) psychology (discipline), (J) SPI-B (names actor). Salience is calculated as the proportion of tweets in that 2-week period that mention the keyword. Bold line represents salience in original tweets; dotted line represents salience including retweets. The area of the bubbles is proportional to the count of sentiments (red=-2,-1; white $=0$; green =+1,+2) towards the keyword. Full bubbles represent sentiments in original tweets only; shaded bubbles represent sentiments accounting for retweets.

Comparing coverage of keywords on twitter (Figure 9, Supplementary Material 9) with that in newspapers (Figure 3), we see that Michie and behaviour change even more strikingly attract neutral and positive sentiment than in print media, and that behavioural economics is similarly absent from the conversation. We also see the same negativity toward Halpern, Behavioural Insights Team \& Nudge just before lockdown. Unlike in media discourse, pre-lockdown negativity is also present for 


\section{Behavioural science representations during COVID-19}

55 psychology, psychologist and behavioural scientist, suggesting that in the public discourse is

56 extended to the discipline and professions of these actors. And unlike in the newspapers, SPI-B is

57 nearly entirely absent from Twitter chatter.

58 Comparing trends in tweets with retweets offers three interesting insights. First, most retweets

59 are of negative sentiment. Nudge and psychologist see a dramatic surge in retweet (but not tweet)

60 salience just prior to lockdown (-1), corresponding with a burst of such negative sentiment.

61 Behavioural Insights Team sees a similar pattern but shifted by two weeks (0). All three keywords

62 see a decrease in tweet/retweet salience and negative sentiment thereafter. Second, Michie sees a

63 surge in tweet and retweet salience before (-2) and after lockdown (4 and 5), both retaining high

64 levels of positive and neutral sentiment. Third, behaviour change surges (starting from period 0 ) and

65 remains high in salience throughout the period, in association with positive or neutral sentiments. For

66 these two keywords (unlike all others), positive sentiments are retweeted most.

\section{$67 \quad$ 3.3.2 Sentiment toward keywords in context of public policy application}

68 How does mention of policy context affect perceptions of behavioural science? Two patterns stand

69 out as distinctive from those in print media. First, a larger majority of positive and neutral sentiments

70 towards behavioural science (Figure 10, Supplementary Material 10) are expressed when this is not

71 mentioned alongside policy applications (top panel), with a burst of retweets of neutral sentiments (-

72 1,0). Second, the patterns of sentiments expressed towards behavioural science when policy

73 application is mentioned (middle panel), and the sentiment expressed towards policy application

74 itself (bottom panel) is closely matched. Just as in print media, we see a prevalence of negative

75 sentiments throughout the period under consideration, with a burst in negativity just before (-1) and

76 at the end of lockdown (3). 


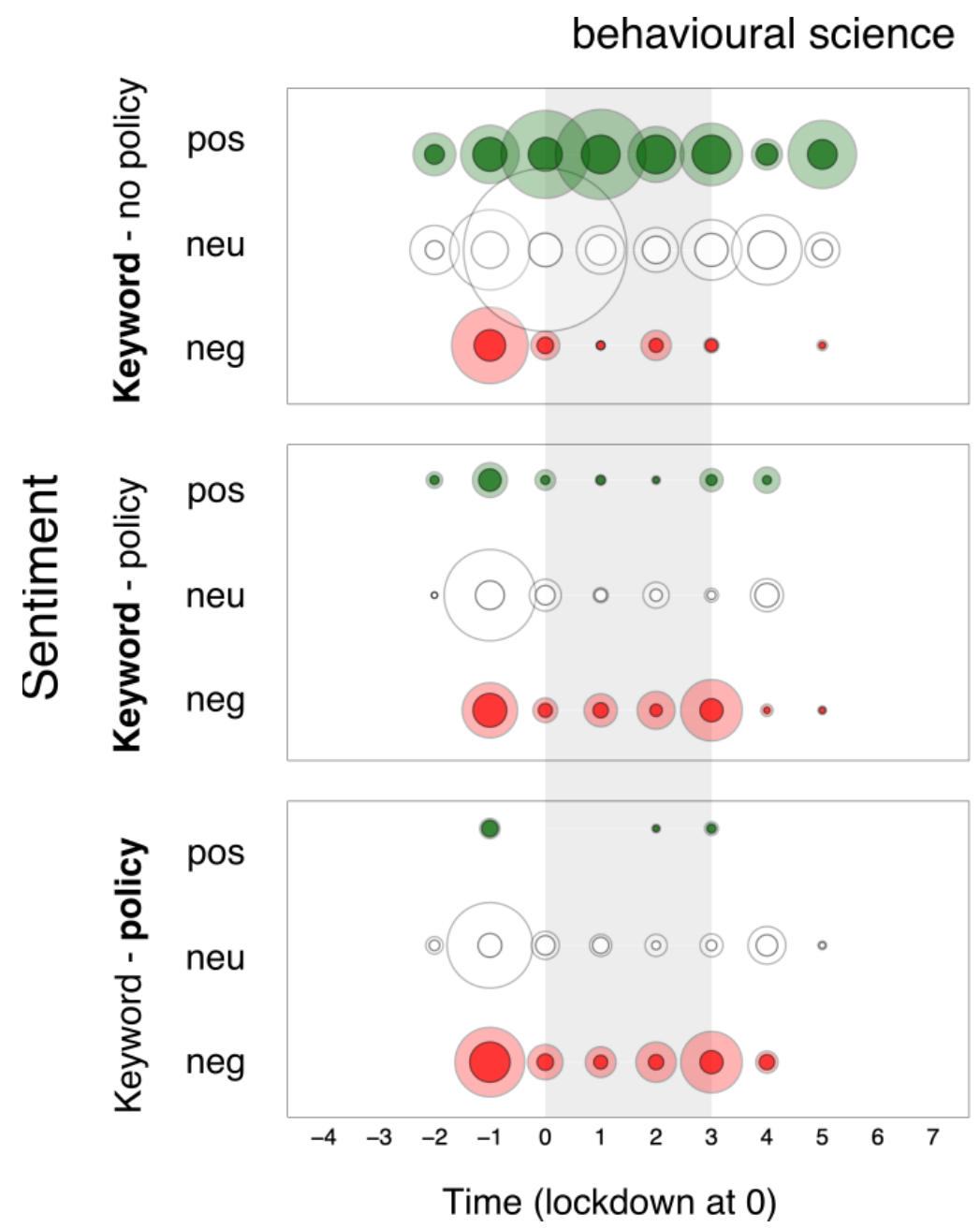

Figure 10: Twitter articles - Sentiment towards "Behavioural Science" separated by sentences that do (top) and do not refer to policy application (middle), and sentiment toward policy contexts of

80 keywords (bottom) over the 8 two-week time period surrounding the first British national lockdown 81 of 2020. The area of the bubbles is proportional to the count of sentiments (red = -2, -1; white =0; 82 green $=+1,+2)$ towards the keyword. Full-colour bubbles represent sentiments in original tweets 83 only; shaded-colour bubbles represent sentiments accounting for retweets.

84 Separating out the sentiments by mention of policy application for the other primary

85 keywords on twitter (Figure 11; see Supplementary Material 10 and 11) allows us to capture three 86 complementary results distinctive from the pattern observed in newspaper articles (Figure 4). First, 87 the striking majority of positive sentiments expressed towards behavioural science keywords is not in 88 reference to policy in association with 3 primary keywords: behaviour change (during lockdown), 89 michie (pre- and post- lockdown), and psychology (during lockdown). Second, keywords which 90 attracted negative sentiment (Behavioural Insights Team, Nudge, Halpern) toward policy-referenced 91 tweets (middle row), attracted similar (not more) negativity in non-policy referenced tweets (top 92 row). Third, negativity expressed toward keywords (middle row) and its policy application (bottom 93 row) when mentioned together, is strongly coupled throughout the set of tweets. 


\section{Behavioural science representations during COVID-19}

94

95

96

97

98

99

100

101

102

103

104

105

106

107

108

109

110

111

112

113

114

115

116

117

118

119

120

121

122

123

\section{Study 3 Thematic analysis of newspaper articles}

\section{$125 \quad 4.1 \quad$ Introduction}

126

127

128

\subsection{Discussion} psychologist). Study 1.

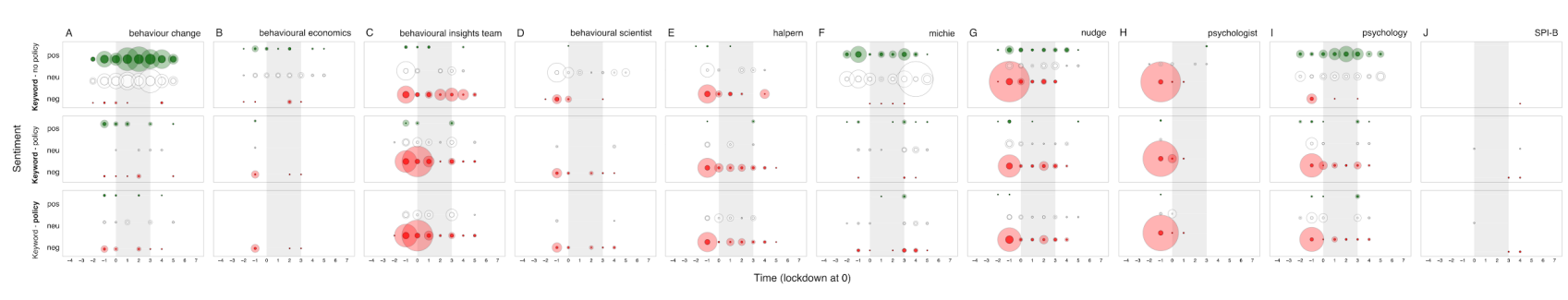

Figure 11: Twitter articles - Sentiment towards the 10 primary keywords separated by sentences that do (top) and do not refer to policy application (middle), and sentiment toward policy contexts of keywords (bottom) over the 8 two-week time period surrounding the first British national lockdown of 2020. The area of the bubbles is proportional to the count of sentiments (red = -2, -1 ; white $=0$; green $=+1,+2)$ towards the keyword. Full-colour bubbles represent sentiments in original tweets only; shaded-colour bubbles represent sentiments accounting for retweets.

As was the case for Study 1, the rapid emergence of negative sentiment toward the embeddedness of behavioural science in the initial phase of Covid-19 restrictions is apparent from Twitter sentiment. behavioural science and its policy actors. This may in part be due to Twitter's succinct communication format (difficult to express contrasting opinions with limited characters) but may also reflect a coupling in actual public opinion. We see some evidence for this: some tweets did express contrasting views (e.g., Michie, nudge, Behavioural Insights Team), but do not seem to hold the same retweet value. In fact, we see that tweets expressing negative sentiment toward behavioural science and its policy counterpart gained most traction overall. Second, we see that negativity is linked to a clustering of Behavioural Insights Team, and Halpern in the pre-lockdown period (just as in print media), but on twitter the negative sentiment also extends to their professions (behavioural scientist;

Further to this, it is not possible to ascertain whether negative sentiment surrounding the behavioural science linked to government policy reflects negative sentiment toward the government transferring onto the involvement of behavioural science, or more general antipathy toward the type of behavioural science approaches employed by the government. It is clear that behavioural science and behavioural change approaches seen as independent of or even in opposition to government policy received a greater deal of both social media attention and positive sentiment, particularly in association with behaviour change or psychology, something highly consistent with findings from

The previous studies provide us with patterns of salience and sentiment toward the behavioural sciences in terms of its perceived 'place' in high-stake public policy from journalistic and social media. To better contextualize these insights and examine how levers (or barriers) of trust and 
129 credibility towards behavioural sciences in contexts of high-stake policy making are constructed in

130 the media, Study 3 utilised a qualitative design, analysing a subset of articles from Study 1.

\section{$131 \quad 4.2 \quad$ Materials and methods}

132 A subsample of articles was selected to include all instances of extreme sentiments $(+2$ or -2$)$. This 133 included a sample of 1) extreme sentiment towards the behavioural science keywords and public policy 134 keywords, 2) extreme sentiment towards the behavioural science keywords, with neutrality towards 135 public policy keywords, 3) neutrality towards the behavioural science keywords and extreme sentiment 136 towards public policy keywords (see Table 2). The total sample of articles $(\mathrm{N}=111)$ was analysed 137 using NVivo 12.

Table 2. Distribution of selected articles across the three time periods (pre-, during-, and postlockdown) and sentiments toward Behavioural science and public policy. Note: some articles appear in more than 1 category (overlap in brackets).

\begin{tabular}{|l|l|l|l|}
\hline & $\begin{array}{l}\text { Sentiment toward } \\
\text { behavioural } \\
\text { science keyword }\end{array}$ & $\begin{array}{l}\text { Sentiment } \\
\text { toward policy } \\
\text { application }\end{array}$ & $\begin{array}{l}\text { Total number of } \\
\text { articles (overlap) }\end{array}$ \\
\hline Congruent positive & +2 & +2 & $8(5)$ \\
\hline Incongruent neutral & +2 & 0 & $2(4)$ \\
\hline Contrast & +2 & -2 & $7(7)$ \\
\hline Incongruent neutral & 0 & +2 & $1(0)$ \\
\hline Incongruent neutral & 0 & -2 & $63(7)$ \\
\hline Contrast & -2 & +2 & 0 \\
\hline Incongruent neutral & -2 & 0 & $8(0)$ \\
\hline Congruent negative & -2 & -2 & $22(9)$ \\
\hline
\end{tabular}

The analysis was deductive, informed by the findings from Study 1. In particular, given the differential coverage of actors, the rise and fall in emphasis on behavioural science and the patterns found in relation to sentiment towards public policy, the qualitative analysis focused on examining three questions which emerged from Study 1:

- How is the UK's approach to the pandemic framed as compared to that of other national approaches, with regards to trust and credibility?

- How are the behavioural sciences discussed and compared to other sciences, with regards to trust and credibility in handling the pandemic?

- How is Behavioural Science introduced in the articles, under which circumstances and how does this framing emphasize trust and credibility in the science?

Specifically, the analysis entailed coding for actors (including scientific actors, government actors and international organisations such as WHO), thematic analysis of sentences describing or 


\title{
Behavioural science representations during COVID-19
}

discussing Behavioural Science, and sentences mentioning different countries approaches to Covid19.

\subsection{Results}

\subsubsection{Behavioural science as part of a national response policy}

Three themes thought to affect credibility of, and trust in behavioural science were identified in relation to the UK's national approach to the pandemic frame: 1) divergence from that of other countries and global policy recommendation; 2) perceived incongruence between the approach and adherence of most senior members of parliament; 3 ) expressed concern by scientific experts and government advisors.

Perception of UK policy response as divergent. Most frequently the UK Covid-19 response is regarded through drawing on a comparative lens, questioning why it deviates so significantly from that of other countries;
"Over the next fortnight, as Italy moved to impose a lockdown, France and Spain began to do the same, and Germany embarked on physical distancing measures coupled with Europe's most extensive testing and contact tracing operation, Britain did comparatively little." (Conn et al., 2020)

In addition, there was frequent mention of how the UK's approach deviated from the one promoted by the World Health Organisation (WHO);

\begin{abstract}
"The key principles from WHO are intensive surveillance. [...] Yet the UK government is no longer testing anyone outside of hospitals, he warned. Prof Costello added: "For me and the WHO people I have spoken to, this is absolutely the wrong policy. It would mean it just let's rip." (Mullin, 2020)
\end{abstract}

Perception of internal incongruence. The lack of trust towards the national response policy is amplified by frequent reports of appearing incongruence between nationally imposed regulations and the perceived adherence to those regulations by parliamentary personnel in public (e.g. during inperson parliamentary activities) or private by some of its prominent members they themselves had been part of developing (e.g. discussion of Dominic Cummings' action as warranted or disregard for regulations);

\footnotetext{
"Professor Susan Michie, director of the Centre for Behaviour Change at University College London, said: "Whilst the PM was telling people to stay at home and keep at least two metres apart from each other, the House of Commons was open for business and face-to-face parliamentary activities were carrying on."Given the transmission routes of touching contaminated surfaces and breathing in virus-laden droplets, it should not come as a surprise to hear that the PM and Health Secretary have tested positive for coronavirus."There are many reasons why those in leadership positions, including in Government, should practise what they preach." (Kirby et al., 2020)
}

Concerns from 'allied' scientific advisors and experts. When critiques like the above come from scientists named and identified as government advisors (e.g., as part of the Scientific Advisory Group for Emergencies), the lack of trust towards government is further elevated. We note that this explains in part the positive sentiment expressed toward Prof. Susan Michie in Study 1 and 2, where her positioning as a scientist who aligns herself with a critical public (often using Twitter to do so) functions to position her as a scientist working for the public good (as opposed to in association with 
government). This is echoed if we look more closely at the most salient tweets in Study 2, where a positive reference to Michie was the third in most retweeted (over 600 times);

"Professor Susan Michie of University College London has praised Nicola Sturgeon and Scotland's approach to COVID-19. Another blow for \#ColonialQuay and BritNats! \#TheNine \#COVID19." (Indy Swim, 2020)

Negative perceptions of the UK policy response (in contrast to that of countries perceived to have successfully suppressed infection rates) are also reinforced by drawing on national and international scientific expert whom, as a collective, comment and critique its incoherence with a globally united response to the pandemic;

\begin{abstract}
"Public health experts and hundreds of doctors and scientists at home and abroad are urging the UK government to change its strategy against coronavirus, amid fears it will mean the epidemic "lets rip" through the population. They say the UK is turning its back on strategies that have successfully brought down the numbers of infections and deaths in other countries." (Boseley, 2020a)
\end{abstract}

The inclusion of scientific experts criticising the Covid-19 response policy opens up assumptions around which scientists might support the national approach, as it is argued to be informed by scientific knowledge. Here we see the coupling of behavioural science and public policy emerge, and the negative sentiment spills into how the behavioural sciences are perceived;

\begin{abstract}
"The government's strategy has at its heart predictions about human behaviour. [...] Which analyses of human behaviour are government scientists relying on? And how comparable are they? Why is fatigue such a problem for new coronavirus measures, which we might expect would command the same kind of support as a war effort, when the state lives with this "fatigue" in the design of the laws and norms that permanently regulate our lives? We can't answer these questions, because the government's scientists aren't yet disclosing what studies and past evidence underpin their current approach. The government's tactic - one might even call it a nudge - is to appeal to the credentials of its advisers and behavioural scientists, and to trust the experts." (Yates, 2020)
\end{abstract}

In conclusion, perceptions of uniqueness, lack of adherence to regulations by parliamentary members, and experts questioning the science informing the UK strategies lead to a media framing of the UK Covid-19 policy response as neither trustworthy nor credible. Behavioural science is initially introduced as what makes the UK response national approach unique and gets caught in the debate.

\title{
4.3.2 Behavioural science relative to other sciences
}

Next, we examined how behavioural science was discussed, in comparison to other scientific approaches, to see which framings did or did not align with public trust and perceived credibility. Here too, we note two themes surrounding trust and credibility: 1) mentions of achievement; 2) scientific experts expressing opposing views.

Mentions of achievement. We identified which scientific experts were named and how articles positioned the expertise of their respective fields. Unsurprisingly (based on the query) behavioural science actors were mentioned most, followed by public health experts and epidemiologists. Scientific disciplines were often mentioned through academic titles, achievements, previous contributions to policy or other contexts of global threat. These introductions consistently lent credibility to the expertise of all scientists (behavioural and other); 


\section{Behavioural science representations during COVID-19}

"Anthony Costello, a UK paediatrician and former director of the World Health Organization (WHO)..." (Boseley, 2020a)

“... a leading behavioural scientist has said. Susan Michie, professor of health psychology at University College London...” (Fisher \& Lay, 2020)

“...the British scientist leading one of the world's most advanced efforts has said. Sarah Gilbert, professor of vaccinology at Oxford University..." ( Thomson et al., 2020)

Sciences in opposition. Scientific experts were also found to express criticism towards other scientific disciplines. We thus examined for which disciplines this occurred and attempted to distill the impact on their credibility in the eyes of the public. While much criticism voiced by experts was leveraged at the national policy approach (as described above) instances of critique at other sciences were also found;

"In March some epidemiologists privately expressed frustration over behavioural scientists advising the government to lockdown later over fears people would tire of restrictions." (Smyth, 2020a)

Such expressions of concern often associated with unnamed scientific actors ('immunologist'; 'epidemiologists') cast doubt on the validity of the contrasted science. In fact, both of the most frequently retweeted tweets identified in Study 2 negatively contrast behavioural science with epidemiologists;

“The government's science advisor is a behavioural psychologist, not an epidemiologist. This is crowd management." (Seymour, 2020)

Similarly, articles reveal drivers of credibility and trust in behavioural science in contrast to other sciences, emphasising the need to consider behavioural implications of different policy options;

David McAdams worries that the health scientists are using simplistic "ad hoc assumptions about behaviour" when complex nudges, such as "effective political leadership", can have big impacts. Understanding motivations properly is vital. Rich people will lock down voluntarily, but poor people may prioritise work. Policies could be tweaked accordingly. [...]. The government's slavish following of epidemiological advice has been a disaster, a lockdown soft enough to leave the UK with a tenth of the world's deaths but hard enough to wipe out up to a third of economic output. (Aldrick, 2020)

We conclude that credibility is extended to characteristics that highlighted the expertise of a particular individual interviewed or quoted in the articles, but that the contrasting perspectives between disciplines, embodied by the voices of different experts criticizing one another, serve as a barrier to trust and credibility in media surrounding what is deemed suitable science to aid toward a health pandemic. The approach of contrasting is similarly but less frequently found in support of behavioural scientists. 


\subsubsection{Key actors and concepts of behavioural sciences}

279

280

281

282

283

284

285

286

287

288

289

290

291

292

293

294

295

296

297

298

299

300

301

302

303

Lastly, we analyse how key concepts and actors within the discipline are introduced. In particular, we consider how articulations construct behavioural science as trustworthy or not, with a focus on its emergent scientific role in high-stake public policy. Here, we separated themes into barriers and drivers of trust and credibility.

Barriers. We observed four barriers to trust and credibility: 1) human irrationality and citizen autonomy, 2) perceived conflicts of interest, 3) behavioural science as being no more than common sense, and 4) the sparse evidence base for key concepts associated with the science.

Humans irrationality and citizen autonomy. As one common frame in media discourse, effectiveness of behavioural science rests on humans acting irrationally. This frame is at times met with resistance in association with the perceptions that the drive for a national lockdown rested on a soft (subconscious) 'nudge' to overcome non-compliance. This perception aligns with criticism of policy-initiated behaviour change as a threat to citizen autonomy (Jones et al., 2013; Leggett, 2014).

Perceptions around conflict of interests. Second, we observe emphasis on semi-privatisation of Dr. David Halpern and the BIT, in particular in the context of strong negative sentiment;

"David Halpern, head of the semi-privatised nudge unit advising Mr Johnson on behavioural science..." (Parker and Hughes, 2020)

“David Halpern, of the part Government-owned Behavioural Insights Team...” (Malnick, 2020)

This is important as the initial coupling of the government's strategy with these actors shows to be paired with perceptions of being profit-driven. Under high-stake policy making, this may represent a source of distrust, as previous studies show that unbiased, reliable and transparent knowledge is associated with independence of other interests (Hendriks, Kienhues, \& Bromme, 2015; Pittinsky, 2015).

Perceptions of behavioural science as no more than common sense. We observe behavioural science discussed 1) through questioning its evidence-based and readiness for policy application, but also 2) through the extent to which it is not just more than common sense knowledge;

"Behavioural science is not a science. The discipline has been hit by a "replication crisis" - results of even well-known studies cannot always be reproduced. Few experimental conditions can be controlled and it is often difficult even to define terms. With little way to prove their hunches wrong, behavioural scientists often assume they are right. That matters when the "science" is applied to policy decisions. While many of behavioural science's insights are mere common sense (people are more likely to turn up for GP appointments when you remind them to), they are dressed up as fact. [...] Besides, behavioural scientists are lobbyists for their own brand of thinking. They are not impartial advisers, and it is time the government stopped treating them as such. They should ditch them altogether. There is evidence enough.” (Gill, 2020b)

"Without an all-out national mobilisation plan for social distancing, are the UK government behavioural and nudge strategies really evidence-based to flatten the peak? Or simply based on models?" (Mullin, 2020)

The use of quotation marks ("') around the word science was found in other articles, which functions to express, at best, reservation and at worst a sense of irony towards the perception that behavioural science is indeed scientific (Weizeman, 2011). Criticisms is expedited as scientific 


\title{
Behavioural science representations during COVID-19
}

experts are introduced as experts of behavioural science aligned with government, yet subsequently identify as an independent experts;

\begin{abstract}
"Boris Johnson got his response to the pandemic "disastrously wrong" because he did not listen to behavioural science experts, a government adviser has said. Delaying lockdown because people would get tired of staying at home was "vigorously opposed" by behavioural scientists feeding into the Scientific Advisory Group for Emergencies, said Stephen Reicher, a member of the Scientific Pandemic Influenza Group on Behaviours, a committee of Sage. Taking a swipe at behavioural theories known as "nudge," he said that one view of human behaviour may be "overly dominating in No 10", leading to "bad decisions"." (Smyth, 2020b)
\end{abstract}

\section{Questioning the scientific evidence base for herd immunity, behavioural fatigue or nudge. Most commonly, the introduction of behavioural science centre around the mention of 'nudges', 'herd immunity' and 'behavioural fatigue';

\begin{abstract}
"If 'behavioural fatigue' truly represents a key factor in the government's decision to delay highvisibility interventions, we urge the government to share an adequate evidence base in support of that decision. If one is lacking, we urge the government to reconsider these decisions," wrote Prof Ulrike Hahn from Birkbeck, University of London, and others.” (Boseley, 2020a)

"Behavioural science works on the basis that people don't always act rationally, and that "nudges" can be more effective at changing behaviour than diktats from authority." (Coyle, 2020)
\end{abstract}

The mention of the above concepts frequently emphasizes concern over their scientific basis. We also observed frequent coupling of 'nudge' 'herd immunity' with public policy application, which in triad is widely criticized in pre- and early lockdown media coverage.

Taken together, these themes question the credibility of the discipline in informing policy and come together in Martha Gill's (2020b) framing of behavioural scientists as not being 'impartial advisers', but rather with disguised motives. Here too, we see the use of quotation marks to question the legitimacy of the scientific basis for psychology and nudge. This framing is crucial, as it is also Martha Gill's tweet that held the highest retweet value (over 900) across the time frame;

\begin{abstract}
"This 'science advisor' [Halpern] is a psychologist. I really can't believe we are attempting to 'nudge' our way out of this with soft science when we need hard science. Epidemiologists are the scientists to listen to." (Gill, 2020a)
\end{abstract}

Drivers. Other articles reveal facilitators of credibility and trust in behavioural science. We identify three themes: 1) scientists who alert to the misuse of scientific evidence in government, and 2) reference to behavioural science's ability to capture public opinion and 3) aid in transparent communication.

Alerting to the misuse of scientific evidence in government. These articles distinguished between scientific expertise offered by behavioural science experts, and how they were translated into government action. They alert that the government appropriated policy recommendations around communication and messaging, which in turn fostered trust in behavioural science from media;

"West also said there had been growing unease among his advisory colleagues about a divergence between the scientific advice and the government's approach. "Those of us on Spi-B have been increasingly concerned about the extent to which the government's approach to the behavioural sciences and the messaging, particularly, has been at 180 degrees from the kind of advice that we have been sending into the Cabinet Office," said West. Members of Spi-B, the advisory group on behavioural 
science, say their recommendations to set very clear and unequivocal messages for the public to follow have frequently been ignored by politicians." (Boseley, 2020b)

Discussion of capturing public opinion and transparent communication. In similar critique of government, there is emphasis on how behavioural science measures are useful for capturing public reactions to policy measures, and that the role of the discipline in understanding how to communicate with the public in a transparent and clear manner was seen as crucial for adherence to new measures, but that this was not taken on board by the government.

We conclude that barriers to trust and credibility arise from questions around the scientific nature of the behavioural sciences, and the purity of intention of behavioural scientists. Drivers of trust and credibility come from decoupling the discipline from the government's response and stressing its uses for public involvement in scientific practice. For this, criticism from behavioural scientists on the government's advisory board (SPI-B) plays a key role, as they stress having felt their advice being 'trashed' (Boseley, 2020b) or 'ignored', echoing the positive sentiment found towards SPI-B in Study 1.

\subsection{Discussion}

Overall, we note three layers of insight. First, the UK Covid-19 policy choices were characterised as unique or divergent in some prominent media publications, with the UK lockdown policy described as delaying harder restrictions based on evidence from behavioural science. This is consistent with patterns in Study 1 and 2 whereby behavioural science as embedded in the UK policy response was frequently characterised by negative sentiment, whereas criticism about these same policies by prominent (independent) behavioural scientists is often characterised by positive sentiment.

Second, we note that the media awards credibility to scientific evidence under high-stake policy making conditions (perceived to be) valid, transparent and reliable. In contrast, credibility is questioned when other scientific experts (from within or outside the discipline) critique public policies or the scientific evidence that support them. References to epidemiologists, public health experts, clinicians, immunologists were common, and in most instances these actors were presented in ways that lent credibility to their expertise. But if these actors were critical of public policies, this was often driven by questions of 'what science' was guiding the choices of policy officials. Hereto (lack of) transparency in addition to a lack of collaborativeness seems to be a driver of outcry.

Third, we observe an additional lever of credibility and trust. Particular scientists from within the discipline may cry out to separate their identity from that of the negatively perceived subgroup. With the over-coupling between lockdown policies and behavioural science in the media, we observed an uprising against its characterisation from closely linked experts. Here credibility is undermined by links to scientific actors thought to have conflicts of interest and question the extent to which their contributions can be evidence-based and unbiased. The contrast of independent and dependent scientists' function to raise awareness of the potential problematic relationship between science and public policy, seen as favouring not the public, but private interests.

\section{General discussion}

\subsection{Summary of findings}




\section{Behavioural science representations during COVID-19}

411 Using two distinct data sources (print media and Twitter chatter) and a mixed methodological design,

412 we have mapped media and public discourse surrounding behavioural science contributions to the

413 first UK lockdown decision of March 2020. We find two distinct clusters of actors and concepts in

414 the behavioural sciences to be received differentially by both the media and public: BIT, Dr David

415 Halpern and 'nudge' are viewed as embedded with the lockdown policy, coupled with negative

416 perceptions, whilst on the other hand, Prof. Susan Michie, Prof. Steven Reicher and the SPI-B are

417 perceived to be speaking out against these policies. Some of those amongst the second set of actors

418 are also publicly associated with less policy-oriented behavioural science activity, surrounding

419 psychological science and behaviour change, which was regarded as substantially more positive. The public eye, however, is drawn more so to the conflict observed between behavioural scientists embedded with policy and those expressing concern over their choices. This, in turn, shows to affect the perceptions of behavioural science most substantially.

How do the behavioural science approaches differ between clusters? One distinction is that positive and neutral sentiment toward behaviour change and psychology was captured by work surrounding the enabling of citizen choice (e.g., handwashing, social distancing), whilst negative and divisive sentiment was associated with behavioural science applied to more embedded and politicised restriction of citizen choice (e.g. lockdown, rules of social isolation). Although this may be so, we also observed negative sentiment toward nudge for not being restrictive enough, so this does not seem to explain the divisive debate entirely. Another contrast between these clusters of actors and concepts is their perceived embedded vs. independent nature from political, as opposed to public, needs. A common issue with embedding scientific practice in policy making is the bias in selection of evidence to suit political needs (Stevens, 2020; Cairney, 2020). In addition, behavioural science as embedded in the Covid-19 policy response was heavily criticized by the media for lack of transparent practices. In contrast, when prominent (independent) behavioural scientists discussed behavioural research as a tool to facilitate public involvement and transparency, its use was rather applauded.

\subsection{Behavioural Science and Covid-19 Response: Implications and Recommendations}

In light of the barriers and drivers observed in relation to trust and credibility around the integration of behavioural science in national policy making under emergency constraints, we discuss recommendations for 1) informing transparent and ethical communication for future behavioural policy making and 2) their immediate use for shaping communication around the behavioural Covid44119 policy measures.

Ethical and transparent policy making. The extent to which behavioural science and the 
citizen autonomy. Further efforts are needed by leaders in the field to clarify the ethical features of different behavioural policy tools (e.g., Lades and Delaney, 2020).

Clarification of behavioural science as a field. The development of behavioural-science driven approaches has been a marked feature of British public policy of the last decade. The integration of a behavioural science stream into the government Covid-19 response policy was debated heavily throughout its initial phases. Public representations of behavioural science reflect a high degree of heterogeneity in the use of the discipline term to represent distinct perspectives and streams of research, something that itself may have contributed to confusion among the public. Structured discussion among key public figures and institutions that use this phrase about the nature and historical origins of their work might be particularly helpful in resolving such confusion and clarifying distinctions between distinctive streams of thought. We hope the analysis in this paper could contribute to this process. The extent to which behavioural science research is seen as a valuable input beyond lay intuitions about human behaviour is another important aspect of field clarification. The readiness of various strands of behavioural science to contribute to emergency situations is another feature of public discourse that has also been reflected in recent academic debates (e.g. IJzerman et al., 2020; Lunn 2020).

Transparency about the role of behavioural science in policy. Overall, the public perception of behavioural science also displays a marked pattern of positivity, with both media and the public expressing positive sentiment about the potential role of behavioural science and behavioural scientists in enabling protective health behaviours, improving citizen involvement in science and pandemic response policy overall. Negative sentiment toward behavioural science and behavioural scientists link to the embeddedness of behavioural science within the lockdown policies of the UK, with suspicions that the 'divergent' UK approach may have reflected insufficient separation between the science advice and political decision making. The extent to which the BIT's financial structure constrains their role in policy was also a feature of public discourse on behavioural science during this period.

We observe that the spread of negative sentiment was centred around a relatively small group of interconnected actors. Furthermore, negative sentiments about high stake policy decisions may also gain more traction than those linked to positive sentiment toward behavioural science. It is beyond the scope of the current study to ascertain whether the perception of UK policy being markedly different from other countries due to behavioural science influence is a reflection of the actual policy process. Even if not, a widespread perception of this nature is something that needs to be addressed in the broader field as it could have consequences for the acceptability of behavioural science in policy as well as potentially detracting from the consistency and perceived trustworthiness of emergency responses.

Implications for current pandemic practice. Behavioural science teams working with government on pandemic response should increase efforts to explain the composition of their teams, engage with the public, and deal promptly with media narratives about the role of behavioural science in policy. Leaders in the field should continue to communicate the role of evidence in informing policy as opposed to setting the broad political direction of policy, and where possible increase efforts to be seen as independent from political processes.

\subsection{Conclusion and Future research}




\section{Behavioural science representations during COVID-19}

This study is based on analysis of public discourse in one country at a time of a major crisis. Future work comparing the discourse behavioural science across different global settings will give a fuller account of the developing influence of emergent behavioural science on policy. Furthermore, the current study is based on samples of print and social media. An interesting area of future study will be to examine public attitudes and representations directly through surveys and interviews.

Generally, an urgent task highlighted by the study of this Covid-19 policy response, is to continue efforts at field definition and role clarification in the behavioural sciences more globally.

\section{References}

Aldrick P., (2020, May 18). Economists must regain the upper hand in the Covid intellectual battle. The Times. Retrieved from: https://bit.ly/3nW5ziQ

Anvari, F., \& Lakens, D. (2018). The replicability crisis and public trust in psychological science. Comprehensive Results in Social Psychology, 3(3), 266-286. https://doi.org/10.1080/23743603.2019.1684822

Arribas-Bel, D., Kourtit, K., Nijkamp, P., \& Steenbruggen, J. (2015). Cyber cities: Social media as a tool for understanding cities. Applied Spatial Analysis and Policy,8(3), 231-247. https://doi.org/10.1080/23743603.2019.1684822

Australian Competition and Consumer Commission (ACCC). (2019). Digital Platforms Inquiry Final Report, Australian Treasury. https://bit.ly/3rAFmss

Bauer, Martin W. and Schiele, B. and Amyot, M. and Benoit, C. (1994) Science and technology in the British press - 1946 to 1986. In When Science Becomes Culture, 11-13 April, 1994, Montreal, Canada. Retrieved from: http://bit.ly/3nZLJDs

Baum, M. A., \& Potter, P. B. (2008). The relationships between mass media, public opinion, and foreign policy: Toward a theoretical synthesis. Annual Review of Political Science, 11, 39-65. https://doi.org/10.1146/annurev.polisci.11.060406.214132

Bian, J., Yoshigoe, K., Hicks, A., Yuan, J., He, Z., Xie, M., Guo Y., Prosperi M., Sallom R. \& Modave, F. (2016). Mining Twitter to assess the public perception of the "Internet of Things". PloS one, 11(7). https://doi.org/10.1371/journal.pone.0158450

Bibo, H., Lin, L., Rui, G., Ang, L., \& Tingshao, Z. (2014). Sensing subjective well-being from social media. In D. Ślęzak, G. Schaefer, So T Vuong, \& K. Yoo-Sung (Eds.), Active media technology (Vol. 8610, pp. 324-335). Warsaw: Springer. https://bit.ly/38EWm84

Boseley, S. (2020a, March 15). Coronavirus: health experts fear epidemic will 'let rip' through the UK. The Guardian. Retrieved from: http://bit.ly/2Mivmnz

Boseley S. (2020b, 25 May). Cummings' actions show government cannot be trusted, says adviser; Sage scientist condemns 'vacuum in the heart of government 'Coronavirus - latest updates. The Guardian. Retrieved from: http://bit.ly/3aO55r7

Cairney, P. The UK government's COVID-19 policy: assessing evidence-informed policy analysis in real time. Br Polit (2020). https://doi.org/10.1057/s41293-020-00150-8 
534

535

536

537

538

539

540

541

542

543

544

545

546

547

548

549

550

551

552

553

554

555

556

557

558

559

560

561

562

563

564

565

566

567

568
Callon, M., Courtial, J.-P., Turner, W. A., \& Bauin, S. (1983). From translations to problematic networks: An introduction to co-word analysis. Social Science Information, 22(2), 191-235. https://doi.org/10.1177/05390188302200200

Chew, C., \& Eysenbach, G. (2010). Pandemics in the age of Twitter: content analysis of Tweets during the 2009 H1N1 outbreak. PloS one, 5(11), e14118. https://doi.org/10.1371/journal.pone.0014118

Choi, J., Yi S., and K. C. Lee . (2011). Analysis of Keyword Networks in MIS Research and Implications for Predicting Knowledge Evolution. Information \& Management, 48 (8): 371381. https://doi.org/10.1016/j.im.2011.09.004

Conn D., Lawrence F., Lewis P., Carrell S., Pegg D., Davies H., Evans R. (2020, 29 April). Revealed: the inside story of the UK's Covid-19 crisis, The Guardian. Retrieved from: http://bit.ly/2MggvKb

Coyle C. (2020, April 12). ESRI research finds 'you will infect others' message most effective in Covid communication. The Sunday Times. Retrieved from: http://bit.ly/3nZMCMi

Damstra, A., \& Vliegenthart, R. (2018). (Un) covering the economic crisis? Over-time and intermedia differences in salience and framing. Journalism Studies, 19(7), 983-1003. https://doi.org/10.1080/1461670X.2016.1246377

Lades, L., and Delaney, L.,. (2020). "Nudge FORGOOD.” Behavioural Public Policy: 1-20. doi: 10.1017/bpp.2019.53.

Della Vigna, S., \& Linos, E. (2020). RCTs to Scale: Comprehensive Evidence from Two Nudge Units. Working Paper, UC Berkeley.https://doi.org/10.3386/w27594

Documenting the Now. (2020). Hydrator [Computer Software]. Retrieved from http://bit.ly/3aMol8r

Dutton, W.H., Law, G., Bolsover, G.\& Dutta, S. (2013). The internet trust bubble: global values, beliefs and practices. Geneva: World economic forum. https://bit.ly/3nZYE8d

Fisher L., Lay K. (2020, March 16). Coronavirus: No 10 facing questions about herd immunity's human cost. The Times. Retrieved from: http://bit.ly/2KxMq8z

Frakes, W. B. and R. Baeza-Yates, editors. 1992. Information Retrieval, Data Structures and Algorithms. Prentice Hall, New York.

Galtung, J., \& Ruge, M. H. (1965). The structure of foreign news: The presentation of the Congo, Cuba and Cyprus crises in four Norwegian newspapers. Journal of peace research, 2(1), 64-90. https://doi.org/10.1177/002234336500200104

Gill, M. [@Martha_Gill], (2020a, 12 March). This 'science advisor' is a psychologist. I really can't believe we are attempting to 'nudge' our way out of this with soft science when we need hard science. Epidemiologists are the scientists to listen to.[Tweet]. Twitter. https://bit.ly/3ryOJsu 


\section{Behavioural science representations during COVID-19}

569

570

571

572

573

574

575

576

577

578

579

580

581

582

583

584

585

586

587

588

589

590

591

592

593

594

595

596

597

598

599

600

601

602

603

Gill, M. (2020b, June 22), The behavioural scientists do more harm than good. The Times. Retrieved from: https://bit.ly/3aWmcXM

Gil de Zúñiga, H., Jung, N., \& Valenzuela, S. (2012). Social media use for news and individuals' social capital, civic engagement, and political participation. Journal of computer-mediated communication, 17(3), 319-336. https://doi.org/10.1111/j.1083-6101.2012.01574.x

Hagberg, A.A., Schult, D.A., \& Swart, P.J. (2008). Exploring network structure, dynamics, and function using NetworkX, in Proceedings of the 7th Python in Science Conference (SciPy2008), Gäel Varoquaux, Travis Vaught, and Jarrod Millman (Eds), (Pasadena, CA USA), pp. 11-15. http://bit.ly/3nXMmx1

Hagman, W., Andersson, D., Västfjäll, D., \& Tinghög, G. (2015). Public views on policies involving nudges. Review of philosophy and psychology, 6(3), 439-453. https://doi.org/10.1007/s13164-015-0263-2

Halpern, D. (2015). Inside the nudge unit: How small changes can make a big difference. Penguin Random House

Happer, C., \& Philo, G. (2013). The role of the media in the construction of public belief and social change. Journal of social and political psychology, 1(1), 321-336. https://doi.org/10.5964/jspp.v1i1.96

Harcup, T., \& O'neill, D. (2001). What is news? Galtung and Ruge revisited. Journalism studies, 2(2), 261-280. http://dx.doi.org/10.1080/14616700118449

Hendriks, F., Kienhues, D., \& Bromme, R. (2015). Measuring laypeople's trust in experts in a digital age: The Muenster Epistemic Trustworthiness Inventory (METI). PloS one, 10(10), https://doi.org/10.1371/journal.pone.0139309

Huber, B., Barnidge, M., Gil de Zuniga, H., \& Liu, J. (2019). Fostering public trust in science: The role of social media. Public Understanding of Science, 28(7), 759-777. https://doi.org/10.1177/0963662519869097

Indy Swim [@indy_swim] (2020, May 28) Professor Susan Michie of University College London has praised Nicola Sturgeon and Scotland's approach to COVID-19. Another blow for \#ColonialQuay and BritNats! \#TheNine \#COVID19 [Tweet]. Twitter. https://bit.ly/3rBjZqF

IJzerman, H., Lewis, N.A., Przybylski, A.K. et al. Use caution when applying behavioural science to policy. Nat Hum Behav 4, 1092-1094 (2020). https://doi.org/10.1038/s41562-020-00990-w

Ioannidis JPA, (2018). All science should inform policy and regulation. PLoS Med 15(5): e1002576. https://doi.org/10.1371/journal.pmed.1002576

Jones, R., Pykett, J., \& Whitehead, M. (2013). Changing behaviours: on the rise of the psychological state. Edward Elgar Publishing.

Jonge, J. D. (2015). Trust in Science in the Netherlands 2015. Den Haag: Rathenau Instituut. 
604

605

606

607

608

609

610

611

612

613

614

615

616

617

618

619

620

621

622

623

624

625

626

627

628

629

630

631

632

633

634

635

636

637

638

639

640

Jovchelovitch, S. (2008). The rehabilitation of common sense: Social representations, science and cognitive polyphasia. Journal for the theory of social behaviour, 38(4), 431-448. https://doi.org/10.1111/j.1468-5914.2008.00378.x

Katsurai, M., Ono, S. (2019). TrendNets: mapping emerging research trends from dynamic co-word networks via sparse representation. Scientometrics, 121, 1583-1598. https://doi.org/10.1007/s11192-019-03241-6

Kerchner, D., \& Wrubel, L. (2020) Coronavirus Tweet Ids. Harvard Dataverse. https://doi.org/10.7910/DVN/LW0BTB

Kim, S. C. , Namkoong, K. , Fung, T., Heo, K. , \& Gunther, A. (2018). Understanding public opinion change of HPV vaccination controversy: Effects of exemplification and the mediating role of projection. Health Education, 118(5), 402-412. https://doi.org/10.1108/HE-01-20180006

Kim, T., Lee, D., Lim, H., Lee, U., Cho, H. \& Cho, K. (2020) Exploring research trends and network characteristics in construction automation and robotics based on keyword network analysis, Journal of Asian Architecture and Building Engineering, 1-16. https://doi.org/10.1080/13467581.2020.1798774

Kirby J., Line H., Hawkins J., (2020, 27 March). Coronavirus: UK sees its biggest day-on-day rise in deaths since outbreak began. The Mirror. Retrieved from: http://bit.ly/38H5vgr

Koplenig A., (2017), Why the quantitative analysis of diachronic corpora that does not consider the temporal aspect of time-series can lead to wrong conclusions. Digital Scholarship in the Humanities, Volume 32, Issue 1, Pages 159-168, https://doi.org/10.1093/1lc/fqv030

Kreps, S. E., \& Kriner, D. L. (2020). Model uncertainty, political contestation, and public trust in science: Evidence from the COVID-19 pandemic. Science advances, 6(43), https://doi.org/10.1126/sciadv.abd4563

Lamberts, R. (2017). The Australian beliefs and attitudes towards science survey. Canberra, Australia: The Australian National University

Leggett, W. (2014). The politics of behaviour change: Nudge, neoliberalism and the state. Policy \& Politics, 42(1), 3-19. http://dx.doi.org/10.1332/030557312X655576

Lindholm, M., Bergman, M., \& Gustav, B., translated by Garrison, H., graphics by Isaksson, P, (2018).Vetenskap \& Allmänhet (VA) Barometer 2017/2018. Retrieved from https://va.se/downloads/varapport2017_3_eng.pdf

Littman, J. (2008). TweetSets. Zenodo. https://doi.org/10.5281/zenodo.1289426

Liu, G. Y., Hu, J. M., \& Wang, H. L. (2012). A Co-word Analysis of Digital Library Field in China. Scientometrics, 91 (1): 203-217.https://doi.org/10.1007/s11192-011-0586-4

Lourenco, J. S., Ciriolo, E., Almeida, S. R., \& Dessart, F. J. (2016). Behavioural Insights Applied to Policy-Country Overviews 2016 (No. JRC100547). Joint Research Centre. https://bit.ly/2M9gBmF 


\section{Behavioural science representations during COVID-19}

641

642

643

644

645

646

647

648

649

650

651

652

653

654

655

656

657

658

659

660

661

662

663

664

665

666

667

668

669

670

671

672

673

674

675

676

677

Lunn, P., (2020). "On the alleged unsuitability of behavioural science for fighting COVID-19", Retrieved from https://go.nature.com/3rBwKl3

Malnick E., (2020, May 17), Government scientists talked up herd immunity despite warnings about early reinfection; Members of influential panel guiding the government's response to the virus warned that the length of immunity was 'unclear'. The Telegraph. Retrieved from:http://bit.ly/34P4a6f

Manning, C.D., Raghavan, P., \& Schütze, H. (2008). Introduction to Information Retrieval, Cambridge University Press.

Mayhew F., (2020, March 19). National newspaper ABCs: Daily Mail closes circulation gap on Sun to 5,500 copies. Press Gazzette. Retrieved from: http://bit.ly/2L4qhhH

McLeod, J. M., Becker, L. B., \& Byrnes, J. (1974). Another look at the agenda-setting function of the press. Communication Research, 1, $131-166$ https://doi.org/10.1177/009365027400100201

Mitchell, A., Simmons, K., Matsa, K. E., Silver, L., (2018). Publics globally want unbiased news coverage, but are divided on whether their news media deliver. Pew Research Center Retrieved from: https://pewrsr.ch/3nUnwy8

Mullin G. (2020, 16 March). Action Stations Is the UK government doing enough to contain spread of coronavirus? The Sun. Retrieved from: http://bit.ly/34SBBVg

Mutz, D. C., \& Soss, J. (1997). Reading public opinion: The influence of news coverage on perceptions of public sentiment. Public Opinion Quarterly, 431-451. https://doi.org/10.1086/297807

Nadelson, L., Jorcyk, C., Yang, D., Jarratt Smith, M., Matson, S., Cornell, K., \& Husting, V. (2014). I just don't trust them: the development and validation of an assessment instrument to measure trust in science and scientists. School Science and Mathematics, 114(2), 76-86. https://doi.org/10.1111/ssm.12051

National Science Board (2016), Science and Technology: public attitudes and Understanding in Science and Engineering Indicators 2016.US National Science Foundation, National Science Board. http://bit.ly/38FEJ8i

Newman, N., Fletcher, R., Kalogeropoulos, A., Levy, D., \& Nielsen, R.K. (2017). Reuters digital news report 2017. Reuters Institute for the Study of Journalism, University of Oxford. Retrieved from: https://bit.ly/2KZjc24

Ordun, C., Purushotham, S., \& Raff, E. (2020). Exploratory analysis of covid-19 tweets using topic modeling, umap, and digraphs. https://arxiv.org/pdf/2005.03082.pdf

Parker G. and Hughes L. (2020, March 16), Battle plan backlash forces PM to recalculate; Inaction on big gatherings increases fears in No 10 that Johnson will be blamed if British death rate outpaces countries in lockdown. Financial Times. Retrieved from: https://on.ft.com/38I1Qiy

Pittinsky, T. L. (2015). America's crisis of faith in science. Science, 348(6234), 511-512. https://doi.org/10.1126/science.348.6234.511-a 
Protess, D., \& McCombs, M. E. (Eds.). (2016). Agenda setting: Readings on media, public opinion, and policymaking. Routledge.

Reynolds, J. P., Archer, S., Pilling, M., Kenny, M., Hollands, G. J., \& Marteau, T. M. (2019). Public acceptability of nudging and taxing to reduce consumption of alcohol, tobacco, and food: a population-based survey experiment. Social Science \& Medicine, 236, 112395. https://doi.org/10.1016/j.socscimed.2019.112395

Robert Bosch Stiftung. (2017) Science Barometer 2017. https://bit.ly/3rHOP1d

Ruggeri, K., van der Linden, S., Wang, C., Papa, F., Riesch, J., \& Green, J. (2020). Standards for evidence in policy decision-making. https://doi.org/10.31234/osf.io/fjwvk

Sanchez-Paramo C., Vakis R., Afif Z. (2019, April 25), Behavioral science in public policy: Future of government? World Bank Blogs. http://bit.ly/3nWAb3L

Sanders, M., Snijders, V., \& Hallsworth, M. (2018). Behavioural science and policy: where are we now and where are we going? Behavioural Public Policy, 2(2), 144-167. https://doi.org/10.1017/bpp.2018.17

Schäfer, M. S. (2012). Taking stock: A meta-analysis of studies on the media's coverage of science. Public Understanding of Science, 21(6), 650-663. https://doi.org/10.1177/0963662510387559

Scheufele, D. A. (2013). Communicating science in social settings. Proceedings of the National Academy of Sciences, 110(Supplement 3), 1404014047.https://doi.org/10.1073/pnas.1213275110

Seymour, R., [@leninology] (2020, March 12) The government's science advisor is a behavioural psychologist, not an epidemiologist. This is crowd management. [Tweet]. Twitter. https://bit.ly/2JsHvVP

Sharma, K., Seo, S., Meng, C., Rambhatla, S., Dua, A., \& Liu, Y. (2020). Coronavirus on social media: Analyzing misinformation in Twitter conversations. https://bit.ly/38H7KAk

Smyth, (2020a, May 23). Lives were lost from acting late, says scientific adviser. The Times. Retrieved from: http://bit.ly/2WSJg1G

Smyth, (2020b, June 24). Isolation fatigue 'was wrong'. The Times. Retrieved from: http://bit.ly/38zULAg

Soroka, S., \& Wlezien, C. (2018). Tracking the coverage of public policy in mass media. Policy studies journal, 47(2), 471-491. https://doi.org/10.1111/psj.12285

Stuart, L., Rayz, J.T., \& Raskin, V. (2013). The Importance of Nouns in Text Processing. Cognitive Science, 35. https://bit.ly/3mWwD07

Sudhahar, S., De Fazio G., Franzosi, R., \& Cristianini , N. (2015). Network analysis of narrative content in large corpora. Natural Language Engineering, 21(1), 81-112. https://doi.org/10.1017/S1351324913000247 


\section{Behavioural science representations during COVID-19}

713

714

715

716

717

718

719

720

721

722

723

724

725

726

727

728

729

730

731

732

733

734

735

736

737

738

739

740

741

742

743

744

745

746

747

748

749

Sunstein, C. R., Reisch, L. A., \& Kaiser, M. (2019). Trusting nudges? Lessons from an international survey. Journal of European Public Policy, 26(10), 1417-1443. https://doi.org/10.1080/13501763.2018.1531912

Stevens, A. Governments cannot just 'follow the science' on COVID-19. Nature Human Behaviour 4, 560 (2020). https://doi.org/10.1038/s41562-020-0894-X

Tyler, T. R. (1980) Impact of directly and indirectly experienced events. The origin of crime related judgments and behaviors. Journal of Personality and Social Psychology, 39, 13-28. https://doi.org/10.1037/0022-3514.39.1.13

Thomson A:, Sylvester R., Smyth C., Wright O. (2020, 11 April). Coronavirus vaccine could be ready by September: Leading scientist ' 80 per cent' sure drug will work. The Times. Retrieved from: https://bit.ly/38F1bOF

Treger, C. (2020). When Do People Accept Paternalism? Experimental Evidence. Experimental Evidence (August 18, 2020). http://dx.doi.org/10.2139/ssrn.3676311

UK Government (2020, December 18) Scientific evidence supporting the government response to coronavirus (COVID-19). http://bit.ly/2KZjKFa

Van Aelst, P. (2014). 12.Media, political agendas and public policy. Political communication, 18, 231. https://doi.org/10.1515/9783110238174.231

Van Bavel, J. J., Baicker, K., Boggio, P. S., Capraro, V., Cichocka, A., Cikara, M., Crockett, M. J., Crum, A. J., Douglas, K. M., Druckman, J. N. Drury, J., Dube, O., Ellemers, N., Finkel, E. J., Fowler, J. H., Gelfand, M., Han, S., Haslam, S. A., Jetten, J... Zaki, J., Zion, S. \& Willer, R. (2020).Using social and behavioural science to support COVID-19 pandemic response. Nature Human Behavior. https://doi.org/10.31234/osf.io/y38m9

Van der Pas, D. J., \& Vliegenthart, R. (2016). Do media respond to party conflict? Debates on European integration in British, Dutch and German party manifestos and newspapers, 19872006. Political Studies, 64(2), 260-278. https://doi.org/10.1111/1467-9248.12187

Weeds, J. \& D. Weir (2005). Co-occurrence retrieval: A flexible framework for lexical distributional similarity. Computational Linguistics, 31(4):439475.https://doi.org/10.1162/089120105775299122

Weizman, E. (2011). Conveying indirect reservations through discursive redundancy. Language Sciences, 33(2), 295-304. https://doi.org/10.1016/j.langsci.2010.10.006

Whitehead, M., Jones, R., Howell, R., Lilley, R., \& Pykett, J. (2014). Nudging all over the world: Assessing the global impact of the behavioural sciences on public policy. Economic and Social Research Council. https://bit.ly/3hwzOuo

Worldometers.info (2020, November 26). UK Population (live). Retrieved from: http://bit.ly/3hmayqC

Yates, T., (2020, May 13), Why is the Government relying on nudge theory to fight coronavirus? The Guardian. Retrieved from: http://bit.ly/38FYBIh 
$7 \quad$ Supplementary Material

751

752

753

754

755

756

757

758

759

760

761

762

763

764

765

766

767

768

769

770

771

772

773

774

775

776

777

778

779

780

781

782

783

7.1 Supplementary Material 1: Table displaying circulation figures by newspaper for 2020 and the newspapers used for the quantitative analysis of Study 1.

7.2 Supplementary Material 2: Defining the A) Lexis Nexis query on the topic of 'behavioural science' between 20th of January and 10th of May and B) query for the 3rd March and the 9th June Twitter data archive.

7.3 Supplementary Material 3: Table of the codebook for primary and secondary keywords used for analysis.

7.4 Supplementary Material 4: Trends in salience and sentiment for keywords per fortnight in newspaper articles (Study 1).

7.5 Supplementary Material 5: Overall frequency of primary keywords A) in newspaper articles (Study 1) and B) on Twitter (Study 2).

7.6 Supplementary Material 6: The dice coefficient formula and co-occurrence strength between keyword pairs per time-period. Pairs are reported in descending order of association in prelockdown.

7.7 Supplementary Material 7: Sentiments towards keywords separated by public policy application mentions for newspaper articles (Study 1).

7.8 Supplementary Material 8: Sentiments towards public policy actors mentioned alongside behavioural science keywords for newspaper articles (Study 1).

7.9 Supplementary Material 9: Trends in salience and sentiment for keywords per fortnight in Twitter data (Study 2).

7.10 Supplementary Material 10: Sentiments towards keywords separated by public policy application mentions for Twitter data (Study 2).

7.11 Supplementary Material 11: Sentiments towards public policy actors mentioned alongside behavioural science keywords for Twitter data (Study 2).

\section{Conflict of Interest}

The authors declare that the research was conducted in the absence of any commercial or financial relationships that could be construed as a potential conflict of interest.

\section{$9 \quad$ Author Contributions}

JGS, AT and SO designed Study 1, 2 and 3. AT lead data processing and analysis for Study 1 and 2. SO lead the data analysis for Study 3. IM, SO, AT, and JGS contributed to sentiment coding for Study 1 and 2. JGS, AT and SO, IM and LDD contributed to discussions and writing the paper.

\section{$10 \quad$ Funding}

No funding was received to complete this research. 
Behavioural science representations during COVID-19

\section{Acknowledgments}

785 We thank Emma Watson and Leonie Hill for their support of this manuscript, and the LSE Covid-19

786 Behavioural Science working group and UCD Behavioural lab group for their feedback.

\section{$787 \quad 12$ Data Availability Statement}

788 The datasets generated and analysed for this study will be shared upon request. 